\title{
XIII.
}

\section{Ueber das Verhalten des Catgut im Organismus und über Heteroplastik.}

\author{
Von Dr. L. von Lesser,
} Privatdocenten der Chirurgie in Leipzig.

(Hierzu Taf. X.)

\section{Theil.}

Lis ter's Experimente und Erfahrungen über die Anwendung der carbolisirten Darmsaiten zu Ligaturen, hat eine grössere Reihe von Untersuchungen über diesen Gegenstand zur Folge gehabt. - Von diesen Arbeiten liefert ein Theil die Resultate über die practische Verwendbarkeit des carbolisirten Catguts zu Ligaturen an grösseren Gefässstämmen, zu Nähten bei plastischen Operationen, zur Uterus- und zur Blasennaht und zur Sicherung des Ovarialstiels. Die oft diametrale Verschiedenheit der hierbei gefällten Urtheile, sowie die statistischen Erhebungen, die zu Ungunsten obigen Ligaturmaterials zu sprechen schienen, fanden ihre Aufklärung, nachdem man sich überzeugt hatte, dass die von Lister gekennzeichneten Vorzüge des Catgut nur dann hervortreten, wenn die antiseptische Wundbehandlung streng durchgeführt wird. Bei nicht aseptischem Wundverlauf ist das Catgut ein unzuverlässiges, selbst ein gefährliches Ligaturmaterial. (Vgl. L. v. Lesser, Die chirurgischen Hülfsleistungen bei dringender Lebensgefahr. Leipzig 1880. S. 20 und 21.) - Ein anderer Theil von Arbeiten hat ein mehr theoretisches Interesse und knüpft an an die Behauptung Lister's, dass die Catgutligaturen zu lebendem Gewebe "organisirt" werden, und dass sie an der Unterbindungsstelle als lebender Gewebsring die Gefässwand verstärken, während sonst das Abfallen der Ligaturen nur dadurch möglich wurde, dass die Ligatur die Continuität des Gefässes durchtrennte (J. Lister, Observations on ligature of arteries on the antiseptic system. The Lancet 1869. April 3). - 


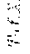
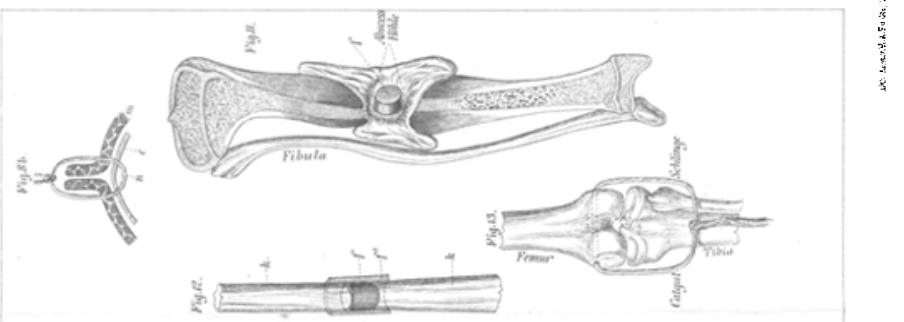

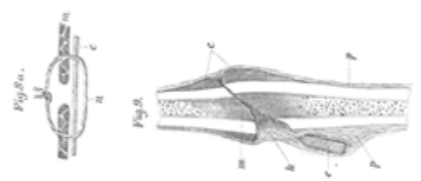
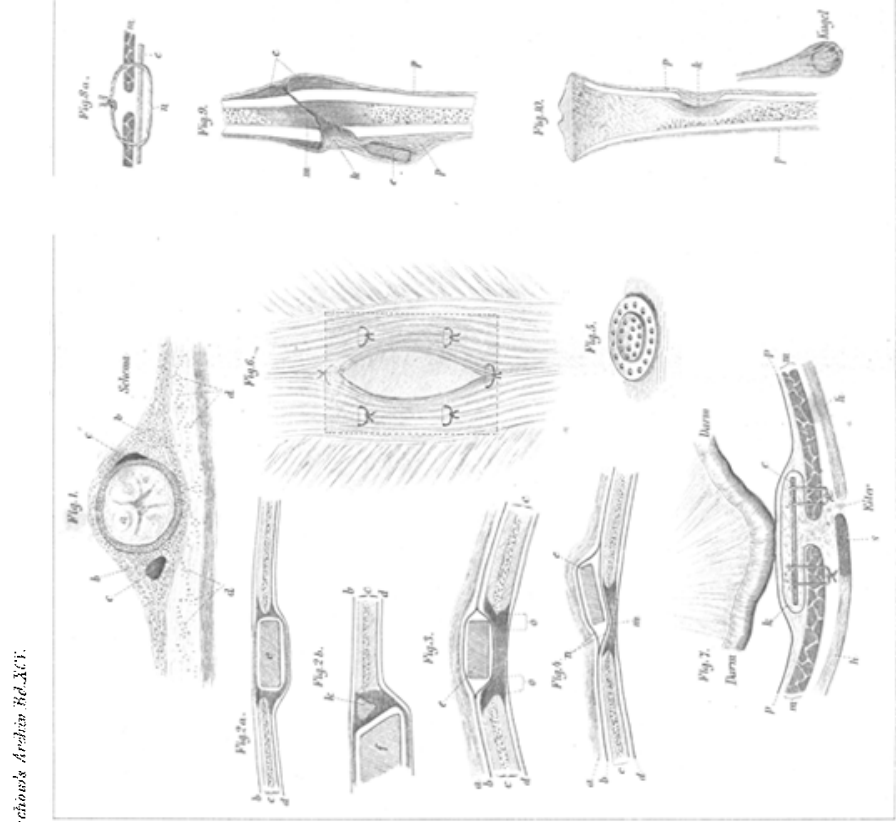
Das Leherraschende und Bedeatsame obiger Thatsache liess die erneute Prüfung der Verwendbarkeit "animaler" Ligaturen überhaupt wünschenswerth erscheinen. - Allein auch hier trat jene auffallende Verschiedenheit der Urtheile hervor über die Art und die Dauer der Vorgänge, welche sich an einer Catgutligatur abspielen. Auch der Vergleich mit verwandtem oder heterogenem Ligaturmaterial, wie gewöhnliche Darmsaiten, Sehnenfasern, Silber, Blei, Eisen, Zwirn, fiel zum Theil zu Ungunsten des carbolisirten Catgut aus. - Die Gründe hierfür sind dieselben, wie bei der practischen Erprobung des genannten Ligaturmaterials. Wie dort die mangelhafte Technik des antiseptic treatment, so hat hier die Schwierigkeit, das letztere an den Versuchsthieren correct durchzuführen, die Verschiedenheit der Meinungen erzeugt. - - Halten wir aber fest, dass Lister seine Resultate nur bei der antiseptischen Wundbehandlung erzielt und auch seine Experimente unter denselben Maassregeln ausgeführt hat, so müssen uns von vornherein alle Berichte über das Verhalten des Catgut in Fistelkanälen, in eiternden Wunden, in Stichöffnungen der Haut bei plastischen Operationen ohne antiseptischen Schutz, ebenso minderwerthig erscheinen, wie das Verhalten von Catgut in Unterbindungswunden von Arterien, wo eine antiseptische Prima intentio nicht erzielt worden war.

Bereits im Jahre 1874 habe ich eine grössere Reihe von Experimenten ausgeführt mit Rücksicht auf die Veränderungen, welche das carbolisirte Catgut in lebenden Geweben erleidet. Ihre Veröffentlichung hat sich verzögert, weil ich dieselben mit einer Reihe weiterer Versuche zusammenfassen wollte, die gleichsam eine weitere Consequenz jener darstellen. - Die Versuche habe ich in den Räumen des pathologischen Instituts zu Berlin ausführen können und sage Herrn Geheimrath Virchow nachträglich meinen herzlichsten Dank.

Da es darauf ankam, dem Ideal der aseptischen Wundheilung, d. h. dem Verlaufe subcutaner Verletzungen möglichst annähernde Verhältnisse zu schaffen, so wählte ich die einfache Methode des subcutanen Durchstichs mit Hautverschiebung, um das. Catgut in den verschiedenen Organen zu deponiren. - Nur bei den Knochen, der Trachea und den Gefässen mussten die Gebilde, natürlich unter antiseptischen Cautelen, frei- 
gelegt und das Catgut um dieselben geschlungen werden. Diese Versuche befinden sich in der Minderzahl. - Zweitens wurden nur Kaninchen zu den Experimenten gewählt (nur ein paar Versuche stellte ich an Fröschen an). - Die Kaninchen eignen sich hierzu besser als Hunde, weil sie bei entzündlichen Erscheinungen rasch durch Bildung eitriger oder käsiger Massen reagiren und so eine grössere Sicherheit vorlag, Versuche mit nicht streng aseptischem Verlaufe sofort ausschalten zu können. - Eine Auswahl der Thiere je nach dem Alter konnte aus äusseren Gründen nicht stattfinden; doch wurden meist mittelgrosse, zwei bis fünf Monate alte Individuen benutzt. - Ich bediente mich einer silbernen, etwa $12 \mathrm{~cm}$ langen Nadel mit einem Oehr an einem Ende und einer platten oder einer dreikantigen Spitze am anderen Ende. Die Nadel war etwas dicker, wie die dickste Sorte des Catgut.

Unter Hautverschiebung wurde diese Nadel in verschiedenen Richtungen und in verschiedener Höhe durch den Thorax durchgestochen und auf der entgegengesetzten Seite so weit herausgezogen, bis der nachfolgende Catgutfaden mit seinem freien Ende in der Einstichsöffnung verschwand. Dann wurde knapp an der Ausstichöffnung das andere Fadenende abgeschnitten, so dass es sich beim Zurückgehen der Hautfalte ebenfalls subcutan zurückziehen musste. Es gelang so, Catgutfäden durch die Lungen und durch das Herz zu legen. - In ähnlicher Weise durchfurchte ich die Bauchhöhle, um die carbolisirten Darmsaiten in den verschiedenen Bauchorganen zu deponiren. Fesselt man die Thiere in entsprechender Weise, so vertragen dieselben obige Eingriffe ohne jegliche Störung ihres Befindens. - Auch subcutan, durch die Wadenmusculatur und durch die Gelenke, führte ich carbolisirte Catgutfäden hindurch, mit ebenso geringer Reaction von Seiten der getroffenen Theile. - So überlebten alle Thiere die oft mehrfachen operativen Maassnahmen beliebig lange. Nur einzelne gingen an zufälligen Krankheiten (Rüude) zu Grunde. - Die meisten wurden getödtet und die Präparate zum Zweck der mikroskopischen Untersuchung in Müller'scher Flüssigkeit und Alkohol gehärtet. - Die mikroskopischen Präparate wurden mit Hämatoxylin oder Carmin gefärbt und in Glycerin eingeschlossen, - Die Untersuchung geschah der Ueber- 
sichtlichkeit wegen meist auf Querschnitten. Doch wurden auch Längsschnitte und Zerzupfungspräparate angefertigt.

I. Subcutanes Bindegewebe. Catgutstïcke (bei J. Gard. ner, Edinburgh, dem Lieferanten Lister's gekauft) von $4-6 \mathrm{~cm}$ Länge meist links oder rechts von der Wirbelsäule subcutan durchgefinht; nur einmal subcutan oberhalb der Symphyse und einmal zwischen Nabel und Rippensaum. Es liegen Präparate vom 11., 18., 22., 32., 36., 61., 64., 82. und 85. Tage aus ebenso viel Versuchen (Vers. 6, 7, 19, 20, 18, 31, 17, 29 und 30) vor. - Bis zum 22. Tage zeigt das Catgut (Cg) fast gar keine Veränderungen. Auf Querschnitten erscheint es entsprechend seiner Fabrication als ein zellenarmes Bindegewebe, im Centrum mit einer geflammten Sternfigur, herrührend von der Zusammendrehung des Materials im Sinne der Längsaxe zu den Cg-Stricken oder Cg-Saiten. - Im Bindegewebe des Querschnitts findet sich eine grosse Zahl feinster (Carbol-) Oeltröpfchen, während in den Spalten der Sternfigur zum Theil grössere bräunliche Oelkugeln oder eine mehr homogene bräunliche Masse (verharztes Carbolöl), die Spalten ganz erfüllend, sich zeigt, welche Masse auch die Oberfläche des Fadens überzieht. Bei 24stündiger Maceration der Cg-Schnitte in Wasser, Kochsalzlösung, zweiprocentiger Carbolsäure werden die Oeltröpfchen und auch die Füllungsmasse entfernt, und innerhalb des gequollenen Fadens erscheint auf gefärbten und ungefärbten Querschnitten die Sternfigur zusammengeschrumpft zu schmalen gleichsam verdichteten Bindegewebszügen. - Auf Längsschnitten finden sich dieselben Verhältnisse, nur dass die bräunlichen Züge als fast parallele und zur Längsaxe des Fadens schief gestellte Streifen erscheinen. - (Ueber das Verhalten des $\mathrm{Cg}$ in verschiedenen Flüssigkeiten siehe weiter unten.)

In den Präparaten vom 11. und vom 18. Tage ist der CgFaden von einer Hülle von verdichtetem Bindegewebe mit sparsamen Wanderzellen und eingelagertem Blutpigment umgeben und so an die Unterfläche der Cutis fixirt und wenig verschieblich. - Am 22. Tage erscheint die Zahl der eingewanderten Zellen beträchtlich. Dieselben umgeben in continuirlicher Schicht die Peripherie des Fadens und sind besonders dicht an den beiden Polen desselben angesammelt, durch welche die der. 
Hautoberfläche parallele Queraxe des $\mathrm{Cg}$ hindurchgeht. Hier erscheint auch von Anfang an das Bindegewebe wegen der cylindrischen Form des Fadens zu dreikantigen Längsschlitzen auseinandergedrängt. Auch findet sich $a b$ und zu Blut in diese Hohlräume ergossen. (Fig. 1 auf Taf. X.)

Einen ganz ähnlichen Befund ergiebt der bis zum 32. Tage subcutan oberhalb der Symphyse belassene Faden, während wir in dem Präparat von der Rückenhaut vom 36. Tage die Einwanderung der Zellen von der Peripherie aus in das Innere des Cg-Querschnittes in grösserem Umfange vor sich gehen sehen. Die Zellen schieben sich so zu sagen in Keilen in das Cg-Gewebe hinein, dasselbe allseitig durchsetzend und zerbröckelnd und zunächst in die vorgebildeten Spalten des zusammengedrehten Fadenmaterials eindringend. - Nach aussen von der Einwanderungszone werden neugebildete Gefässlumina sichtbar. Auch das in die dreikantigen Spalten ergossene Blut zeigt nicht nur reichliche eingewanderte Zellen, sondern auch bereits Bildung jungen Bindegewebes an Stelle des Blutextravasats.

Bemerkenswerth sind ein Präparat vom 61. und ein Präparat vom 64. Tage. In beiden Fällen wurde derselbe Faden benutzt. - Das unterhalb des Thorax unter die Haut geschobene Cg-Stück vom 61. Tage erscheint völlig unverändert; in dem umgebenden auseinander gedrängten Bindegewebe die Spindelzellen an der Grenze des $\mathrm{Cg}$ etwas dichter und parallel der Oberfläche des Cg-Fadens gelagert; nur spärliche rundliche Zellen von beträchtlicher Grösse an der Peripherie des Cg vorhanden, und zwar in den Winkeln, wo auch noch Blutpigment sich findet (s. o.), (Vers. 31). - In Versuch 17 wurde das $\mathrm{Cg}$ unter die Thoraxhaut am Rücken gebracht und 64 Tage daselbst belassen. - Hierauf erscheint das Cg als ein bräunlicher, punctirter Streifen, kaum von dem umgebenden Bindegewebe unterscheidbar. - Unter dem Mikroskop sehen wir auf Querschnitten ein plattgedrücktes Oval, in dessen einer Schmalseite eine grössere Menge freien und in grossen Zellen eingeschlossenen gelblichen Pigments angehäuft ist, während der übrige Raum des Ovals von zierlichem sehr zellenreichem jungen Bindegewebe ausgefüllt ist. An der Peripherie wird das Oval von einem faserigen Ring umgeben, in welchem spärliche runde Zellen und Pigmentkörnchen sich finden. 
Das Präparat aus Versuch 29 zeigt das Cg am 82. Tage nach der subcutanen Einsuhiebung. Sohon makroskopisch unterscheidet man auf dünnen Querschnitten dunklere Flecken und hellere Partien in dem an Stelle des $\mathrm{Cg}$ vorhandenen ovalen Gewebsquerschnitt. - Erstere entsprechen jenem zellen-, kernreichen jungen Bindegewebe, wie wir es bisher angetroffen haben. Die helleren Flecken entsprechen jungem Narbengewebe, das reichliche Bindegewebsfasern und Bündel und nur wenig Zellen zeigt. Dazwischen finden sich hier und da, und besonders wiederum in der Nähe der Spitzen des Ovals am reichlichsten, gelbliche Heerde, die aus Nestern von grossen, epithelioiden platten Zellen bestehen. Letztere sind entweder diffus gelblich gefärbt, oder es finden sich um den Kern zahlreiche, kleinere und grössere Körner von brauner bis schwarzbrauner Farbe angehäuft, die den Zellennestern ein bräunliches bis graubraunes Ansehen verleihen. Die Menge des jungen Narbengewebes ist auf verschiedenen Querschnitten bald mehr, bald weniger reichlich. - Die Begrenzung des Ovals nach aussen bildet ein zellenarmes Bindegewebe, in dem mehrfache grössere und namentlich kleinere Gefässe um das Oval herum sichtbar sind.

In Versuch 30 waren vier sehr lange Stücke $\mathrm{Cg}$ am Rücken subcutan gelagert worden. - Nach 85 Tagen sind nur noch drei Stücke nachweisbar. - Das oberste und das unterste Stück zeigen sich stark verdünnt an den Stellen, wo sie über den Proc. spinosi der Wirbelbögen gelagert gewesen waren. - Auf mikroskopischen Querschnitten ist das Cg mit dem in den dreikantigen Räumen vorhandenen Blutextravasate zu einer platten Spindel von jungem, aber sehr faserreichem Bindegewebe verschmolzen, dessen Zellen theils noch sternförmig sind, theils spindelförmig und an einzelnen Stellen perlenschnurartig zu Zügen angeordnet erscheinen. - So durchziehen dichtere und von grösseren Spindelzellen durchsetzte Bindegewebszüge, Blattrippen ähnlich den Querschnitt. - In den dreieckigen Räumen ist das Bindegewebe noch sehr zellenreich und durchsetzt von grossen, Myeloplaxen-älnnlichen Zellen, mit reichlichen, zum Theil regelmässig angeordneten Kernen und reichlicher Einlagerung von feinkörnigem Pigment. - Solche Zellen begrenzen auch an andern Orten die Längsseite der Cg-Spindel, dort besonders wo Reste des Blutextravasates sich finden. 


\section{7}

Anm. Das in den verschiedenen subcutanen Lymphsäcken von Fröschen deponirte Cg (Vers. 2, 3, 11a u. 11b) zeigt in den ersten Tagen einen Belag an der Oberfläche von farblosen theils runden, theils kolbigen Zellen (Präp. vom 3. Tage). Dieselben liegen in verschiedener Dicke dem $\mathrm{Cg}$ auf, so dass die Oberfläche zum Theil höckrig erscheint. Späterhin erscheint das Cg durch Gefässschlingen führende Stränge fixirt, die netzartig das $\mathrm{Cg}$ umspinnen. Noch später sehen wir die gegenüberliegenden Wände des Lymphsackes durch eine sulzige, von Gefässschlingen durchzogene Masse verklebt, in welche das $\mathrm{Cg}$ eingebettet ist. Mikroskopisch bietet diese Masse eine reichliche Anhäufung von farblosen Zellen, zum Theil reichliche Kerne in einem körnigen Protoplasma eingebettet ohne sichtbare Zellencontouren. An anderen Stellen liegen die Zellen bereits in einem Netzwerk von Fibrinfäden.

II. Von den durch Kaninchenmuskeln durchgesteckten Cg-Stücken liegen Präparate vom 11., 22., 31., 37. und 85. Tage vor. - In Versuch 6 (Präp. vom 11. Tag) nehmen sich die in den Mm. crurales steckenden Cg-Stücke, wie halb durchscheinende Narbenstränge aus. Zum Theil ragen sie aus der Muskelsubstanz heraus und zeigen sich eingekapselt auf der Muskeloberfläche. - Auf mikroskopischen Querschnitten stellt sich das $\mathrm{Cg}$ wie zerklüftet dar und an der Peripherie wie ausgenagt mit flachen buchtigen Aushöhlungen. - In die Zerklüftungen oder Spalten erstreckt sich das umgebende zellenreiche Bindegewebe oder sie sind, wie grösstentheils, mit geronnenem Blute ausgefüllt, wie solches auch besonders an den Polen der Queraxe des Schnittes an der Peripherie dem Cg anliegt. Das um das $\mathrm{Cg}$ liegende Bindegewebe zeigt in einem feinfaserigen Netze reichliche Zellen eingelagert, deren Zahl desto grösser wird, je näher dieselben an das $\mathrm{Cg}$ herankommen, oder wo das Gewebe direct an das $\mathrm{Cg}$ sich anschliesst. Wo dagegen an der Oberfläche des $\mathrm{Cg}$ ein Blutgerinnsel sich aufgelagert findet, da treten an der Grenze von dem zellenreichen Bindegewebe und dem Blutgerinnsel grosse mit dunklen, regelmässig angeordneten Kernen versehene Zellen auf. Ebensolche finden wir mitten in dem Blutgerinnsel, mag dasselbe dem $\mathrm{Cg}$ aufliegen oder in dessen Spalten eingeschlossen sein. 
Aehnlich zerklüftet erscheint das $\mathrm{Cg}$ in den Halsmuskeln (Vers. 19) nach 22 Tagen. Auch liegt hier körnige Masse in den Spalten. - An der Peripherie ist die Zerfaserung bedeutender. Zwischen den einzelnen Fasern liegt ein zellenreiches Netzwerk und setzt sich direct in die neugebildete zellenreiche Hülle des $\mathrm{Cg}$ fort. Nur dass hier das zellenreiche Gewebe von Balken durchzogen wird, die ebenfalls ein grossmaschiges Netz bilden und innerhalb deren die grosskörnigen Zellen dicht an einander, ohne Zwischenmasse gelagert sind. (Gefässanlagen?)

In Versuch 21, im Präparat vom 31. Tag erscheint in der That das zellenreiche, das $\mathrm{Cg}$ einschliessende Gewebe von jungen Gefüssen durchzogen, die zum Theil mit Injectionsmasse, theils auf Querschnitten und theils auf Längsschnitten, gefällt erscheinen. (Es war nach dem Tode des Thieres eine Carminglycerinlösung in die Bauchaorta gespritzt worden.)

In Versuch 25 war das $\mathrm{Cg}$ quer durch den linken Cruralis gesteckt worden. Das Thier wurde nach 37 Tagen durch doppelten Pneumothorax getödtet, die Aorta mit Carminglycerin unmittelbar darauf injicirt. - Das $\mathrm{Cg}$ erscheint durchweg von einem sehr zellenreichen, aber auch faserreichen und von jungen Gefässen durchzogenen Bindegewebe mit engmaschiger Anordnung des Fasernetzes umgeben, zum Theil auch ersetzt. An einzelnen Stellen nehmlich erscheint das Cg selbst fast unverändert innerhalb der bindegewebigen Einbettung; an anderen dagegen ist nur das Innere des Fadens, oder ein mehr peripherer Theil erhalten, während die peripherische Mantelzone oder ein beliebiges Stück des Fadencylinders durch jenes zellenroiche Bindegewebe sich vertreten zeigen. Der Einkapselungsprozess sowie die Usur des Fadens haben hier offenbar unregelmässig an den verschiedenen Stellen stattgefunden. - Am 85. Tage nach der Einführung in den M. cruralis wurde ein dicker Cg-Faden in Versuch 30 untersucht und zwar sowohl auf Querschnitten wie auf Längsschnitten. Auf letzteren erscheint das $\mathrm{Cg}$ vielfach ganz unverändert, wie frisch geschnittene und in Glycerin eingelegte Cg-Präparate von festem, parallel faserigem Gefüge. Andere Schnitte geben das Bild, als wenn die faserige Schichtung des $\mathrm{Cg}$ gelockert und das $\mathrm{Cg}$ ersetzt wäre durch ein Gewebe, das aus einem dichten Netz feiner Fasern besteht, in dem an ein- 
zelnen Stellen spärliche, an anderen Stellen reichliche Zellen eingelagert sind, so dass das Gewebe bald frischem Narbengewebe und bald jungem Bindegewebe entspricht. In letzterem finden sich ab und zu eingestreut grössere Bröckel des. ursprünglichen $\mathrm{Cg}$, gleichsam sequestrirt. - Einzelne Partien der Querschnitte, sind dunkeler gefärbt; auf Längsschnitten erscheinen sie als schief angeordnete Streifen. Hier finden wir freies bräunliches Pigment und zahlreiche grosse Riesenzellen mit Pigmentkörnern im Innern.

III. Um Knochen wurde das $\mathrm{Cg}$ in zwei Versuchen (Vers. 28 und 29) derart geführt, dass nach Freilegung der Tibia und Spaltung von deren Periostmantel, das Cg subperiostal um die Diaphyse in Ringform geschlungen wurde. Verschluss der Hautwunde durch dünne Cg-Faden. Das Cg-Präparat blieb 15 und in Versuch 2982 Tage liegen. - Mikroskopisch konnte nur das Präparat vom 15. Tage untersucht werden. - Das $\mathrm{Cg}$ erscheint auf Querschnitten ganz unverändert in einem Schlitz des Periostes steckend. Die benachbarte Knochenpartie zeigt keine Veränderungen. In den dreikantigen Räumen des Schlitzes zu beiden Seiten des Cg liegt ergossenes Blut und in diesem eingebettet, oder aus dem benachbarten Bindegewebe in das Blutgerinnsel hineinragend finden wir zahlreiche zum Theil sehr grosse Riesenzellen mit mehrfachen Kernen, einzelne mit Morgenstern-ähnlichen Stacheln besetzt. - Solche Zellen liegen an einzelnen Stellen der Peripherie des $\mathrm{Cg}$ direct an und zwar indem sie mit ihrem grössten Längsdurchmesser der Cg-Peripherie sich parallel lagern oder indem sie radiär auf letztere gerichtet sind. - Aehnliche Riesenzellen finden sich weiter entfernt vom $\mathrm{Cg}$ in dem Periostgewebe selbst, besonders um Gefässquerschnitte gelagert. - Die kleinzellige Infiltration des Periostgewebes ist ebenfalls am stärksten um die Gefässe herum, sonst spärlich.

IV. Zur Prüfung des Verhaltens des Cg innerhalb der Gelenke wurde durchgehends das Kniegelenk, als das am sichersten zu handhabende, benutzt. Die Durchstechung geschah stets mit Hautverschiebung. (Vers. 5, 24, 25, 20, 23 und 27.) Doch trat ab und zu ein Tropfen Synovia aus (Vers. 5). Die ersten drei Tage nach Einführung des $\mathrm{Cg}$ zeigten sich die Gelenke geschwollen, zum Theil die Haut däüber geröthet und es bestand. 
Empfindlichkeit bei Druck, besonders in Versuch 20. Dann trat aber durchweg Rückgang aller entzündlichen Erscheinungen ein und die Thiere blieben munter. Nur in einem Falle persistirte eine wahrscheinlich auf directe Läsion zurückführbare Schwellung der oberen Tibiaepiphyse (Vers. 20) bis zum Tode. - Meistens wurden $\mathrm{Cg}$-Stücke gleichzeitig in beide Kniegelenke eingeführt. - Bei der Section fanden sich die Stränge von $\mathrm{Cg}$ theils unterhalb, theils oberhalb der Patella, theils am lig. int., theils am Lig. ext. in die Subsynovialis eingebettet und auch subcutan aus der Gelenkkapsel an die äussere Fläche derselben hervorragend.

In Versuch 25 lag das Cg-Stück als plattes Band zusammengerollt in einer kleinen mit Synovia gefüllten Höhle, nach oben und innen von der linken Patella, welche Höhle wie ein Recessus direct mit dem Kniegelenke in Verbindung stand. Auch in Versuch 20 fand sich das $\mathrm{Cg}$ zu einem goldgelben Knäuel zusammengeballt und in das Lig. mucos. an der Aussenseite des Gelenkes eingebettet. In der Synovialis in der Nachbarschaft des $\mathrm{Cg}$ subsynoviale Ecchymosen, oder Einlagerung von bräunlichem Pigment. - Die Gelenke wurden am 13., 30., 37., 39. und 98. Tage nach Einführung des $\mathrm{Cg}$ untersucht. - Mikroskopisch erscheint das subsynovial liegende $\mathrm{Cg}$ vom 13. Tage unverändert, das umgebende auseinander gedrängte Bindegewebe von zahlreichen Zellen durchsetzt, deren Zahl um das $\mathrm{Cg}$ am dichtesten wird. - In den $\boldsymbol{A}$-Räumen ergossenes Blut zoigt wiederum grosse, Pigmentkörner haltige Zellen.

Besonders interessant ist die Entersuchung des an der Aussenseite des Kniegelenkes in Versuch 25 in einer Art Gelenkrecessus liegenden $\mathrm{Cg}$-Stückes vom 37. Tage. Als äusserste Schicht sehen wir hier ein Netzwerk feinster Fäden, ausgefüllt von reichlichen kleinen Rundzellen. Es mag dies eine Gerinnungsschicht sein aus der Synovialflüssigkeit. Auf diese Schicht folgt nach dem Centrum zu eine zweite aus concentrischen Lagen einer streifigen zellenarmen Substanz bestehende Hülle (Fibrinschicht). Und erst innerhalb dieser einkapselnden schichten finden wir ein junges zellenreiches Bindegewebe, worin reichliche grosse mit Pigmentkörnern erfüllte Zellen sich finden. Und ganz in der Mitte nur etwas excentrisch liegt der Ueberrest des Cg-Fadens aus zerbrochenen, zerklüfteten, grösseren und kleineren 
und kleinsten Stücken der Cg-Substanz bestehend, während die Lücken und Spalten überall von jungem, sehr zellenreichem Bindegewebe durchwuchert sind. - Die Wand der Kapsel, in der das $\mathrm{Cg}$ gelagert war, zeigt an der freien, der Höhle resp. dem $\mathrm{Cg}$ zugewandten Fläche eine sehr zellenreiche, von einem Netzwerk feinster Fäden durchsetzte Schicht, wie an der Oberfläche des $\mathrm{Cg}$, nur dass diese Gerinnungsschicht hier viel dicker ist. Nach aussen zu folgt eine Schicht von gelocktem, zellenarmen, faserigen Bindegewebe und schliesslich ein weitmaschiges, von grösseren Gefässstämmen durchsetztes deIn subcutanen entsprechendes Gewebe.

Das Cg in Versuch $20 \mathrm{zu}$ einem goldgelben Knäuel zusammengeballt und im Lig. mucos. an der Aussenseite der Quadricepssehne eingebettet, ist (nach 39 Tagen) in einen Strang von kernreichem Bindegewebe verwandelt, das von dem Fettgewebe des Lig. mucos. direct umgeben wird. Aus letzterem treten grosse Gefässe (Carmininjection in die Aorta) an den Bindegewebsstrang heran. Im letzteren liegen verstreut Gruppen grosser, vielkerniger Zellen, eine und die grösste hiervon in der Axe des Stranges, welche durch Carmin nicht gefärbt worden sind und als gelblicher Heerd sich darstellen. - Die Bindegewebszellen an einzelnen Stellen haben Sternform, an einzelnen Stellen auch bereits Spindelform angenommen. Vom ursprünglichen $\mathrm{Cg}$ ist nichts mehr vorhanden. - Der Theil dieses Cg, der frei in's Kniegelenk hineinragte, zeigt eine Aussenschicht von concentrisch geschichteten und von in gleicher Weise concentrisch angeordneten Spindelzellen durchsetztem Bindegewebe. Nach innen folgt ein junges Bindegewebe, das jedoch in der mehr stabilen Form des von Bindegewebsfasern durchzogenen und mit Spindelzellen versehenen Gewebes erscheint. - Dabei ist die sternförmige Figur des ursprünglichen $\mathrm{Cg}$ noch vorhanden. Auch finden sich hier und da einzelne Cg-Bröckel eingeschlossen. - Das $\mathrm{Cg}$, welches 98 Tage (Vers. 27) im Lig. mucosum dicht am Patellarrand gelegen hatte, erscheint als ein bindegewebiger Strang. Dessen oberflächlichere Partie zeigt aufsteigende Gefässschlingen wie in Granulationen und reichliche spindelförmige Zellen. Die tiefere Schicht, also die Anhaftungsschicht des $\mathrm{Cg}$ Bandes an die Unterlage ist arm an Gefässen und kleineren Zellen. 
Y. Gg-Ligaturen an Gefässen wurden principiell nicht angelegt. Doch kamen einige Ligaturen zur Untersuchung, die wegen anderweitiger Eingriffe, theils an der A. carotis (Vers. 28 und 29) theils an der V. jugul. (Vers. 23 und 25) angelegt worden waren.

Die Arterienligaturen (vom 16. und vom 82. Tage) wurden genauer untersucht. - Das Cg rom 16. Tage lag in eine gelbliche Masse eingebettet un die Carotis, an der keine entzündlichen Veränderungen wahrnehmbar waren. - Mikroskopisch zeigt sich die Gefässwand, besonders an der engsten Stelle. des ligirten Gefässes, von zahlreichen Rundzellen durchsetzt. Dieselben bilden auch eine zellenreiche Hülle um das sonst intacte $\mathrm{Cg}$, hier und da buchtenförmig in seine Oberfläche sich einlagernd. -82 Tage hatte das $\mathrm{Cg}$ um die Carotis eines alten weissen Kaninchens gelegen. Dasselbe erscheint in situ als ein gelblicher avaler Heerd, entsprechend dem Knoten. Das peripherische Carotisstück endet oberhalb spitz ausgezogen und durch einen feinen Streifen mit dem gelben Knoten in Zusammenhang. - Blut findet sich in dem peripherischen Carotisstück nur wenig. Ttwa $\frac{1}{2} \mathrm{~cm}$ oberhalb und bis zum Knoten ist das Gefäss leer, durchscheinend. Mikroskopisch zeigen die Querschnitte durch den gelblichen Knoten bei schwacher Vergrösserung scheinbar die Structur des Cg. Bei stärkeren Vergrösserungen bemerkt man, dass zwar die Sternfigur des ursprünglichen $\mathrm{Cg}$ persistirt, sowie einzelne Theile. Dagegen ist der übrige Raum von jungem, neuem Bindegewebe ausgefüllt, dessen Zellen nicht reichlich sind, und spindelförmig oder mit mehrfachen Fortsätzen ausgestattet erscheinen. - Grössere, spindelförmige mit blasenförmigen Körnern gefüllte Zellen finden sich nur einzeln. - So zeigt sich der $\mathrm{Cg}$-Knoten der Form nach scheinbar erhalten. Und doch ersetzt ihn innerhalb derselben Grenzen ein neu gebildetes Gewebe.

Die Venenpräparate vom 25. und vom 47. Tage (Vers. 23 und 25) sind bei ähnlicher Gelegenheit, wie die Ligaturknoten der Arterien gewonnen. In Versuch 23 lagen an der V. jugul. dextr. drei Knoten in eine gelbliche, sulzige, von schwarzen Punkten durchsetzte Masse eingebettet. - Mikroskopisch zeigen dieselben (Präparat vom 25. Tage) das Cg ganz 
unverändert, allein umgeben von zellenreichem Bindegewebe, in dem erweiterte Gefässlumina (Injection mit Kollmann's Carminlösung) sichtbar sind. Rings um das Cg bilden die Rundzellen einen dichten $\mathrm{Wall}$, in welchem die direct an das $\mathrm{Cg}$ grenzende Schicht fast aus lauter grossen, mehrkernigen, rundlichen und ovalen Zellenleibern besteht.

VI. In Versuch 31 wurden drei Cg-Ligaturen lose um die Trachea gelegt. - Nach 61 Tagen fand sich blos ein Knoten an der Vorderseite der Trachea wieder. Derselbe zeigt als Kern das unveränderte, an der Peripherie buchtig ausgenagte Cg-Material, eingeschlossen in zellenreiches Gewebe, wo wiederum dicht um das $\mathrm{Cg}$ grosse Zellen sich gelagert finden.

VII. Auch durch den Thorax wurden Cg-Fäden mit Hülfe der silbernen Nadel in verschiedenen Richtungen durchgezogen. Zunächst bei Fröschen (Vers. 8 und 14). 4 Präparate wurden untersucht, 3 vom 8. Tage, 1 vom 20. Tage nach der Durchführung. - Von den ersten drei Präparaten fand sich in einem Falle das $\mathrm{Cg}$ zwischen Lunge, Eileiter und rechtem Blasenhorn in eine obige Organe mit einander verklebende sulzige Masse eingehüllt. Die Fadenenden ragten aber sowohl am Rücken wie links vom Proc. xyphoides aus der Haut hervor. In der Bauchhöhle viel freie Flüssigkeit. - Ein Blutextravasat subserös in der vorderen Bauchwand und in den Rückenmuskeln. - Im zweiten Falle war nur ein Blutextravasat im linken Pectoralis sin. vorhanden. Von hier aus drang das Cg durch das Pericardium, den rechtsseitigen Leberrand bis in die rechte Lunge. Das Pericard voll flüssigen Blutes, röthliche Auflagerungen an der vorderen Herzfläche, hinten Verklebungen zwischen Herz und Pericard. - Unter ähnlichen Verhältnissen wurde im dritten Falle das $\mathrm{Cg}$ zwischen Vorhof und Bulbus aortae eingelagert gefunden. - Der Frosch, der 20 Tage gelebt hatte, trug das Cg in der rechten Lunge, ohne dass in der Umgebung des Fadens entzündliche Veränderungen nachweisbar waren.

Die anderen hierher gehörigen Versuche (Vers. 22, 19, 13 und 26) betreffen Kaninchen. - In Vers. 22 war das Thier septisch nach 2 Tagen zu Grunde gegangen. Das Cg durchfurchte den unteren linken Lungenlappen, ging durch das Pericard, zwischen dessen Parietalblatt und der hinteren Herzwand. 
und senkte sich auf der anderen Seite in die rechte Lunge ein. Die Lungen waren derb, zum grassen Theil lufteer, links unten blutig infiltrirt. Acute Peritonitis, Pericarditis und entsprechende Veränderungen der Bauchorgane. - In Vers. 19 war der CgFaden (nach 22 Tagen) retropleural durchgestochen, vom linken 2. Intercostalraum eindringend und dort zum Theil in den Muskeln liegend. Der Faden verlief an der hinteren Wand der linken Pleurahöhle, nach der Wirbelsäule zu, dann hinter Aorta und Oesophagus bis an die Grenzlinie des Mediastinum post. Lungen und Pleurahöhlen ohne Veränderungen. - Der Versuch 13 bietet ein besonderes Interesse. Hier wurde das $\mathrm{Cg}$ quer durch die obere Thoraxhälfte des jungen Thieres gezogen. Nach 51 Tagen wird das völlig muntere Thier verblutet. - Im 2. Intercostalraum rechts und links finden sich kleine Blutaustritte in den Intercostalmuskeln, in beiden Pleuren und im Herzbeutel nur Spuren einer wasserhellen Flüssigkeit. - Das Cg, adhärent an der Thoraxwand in der Axillarlinie in der Höhe des 3. Intercostalraumes links, geht von da als dicker, abgeplatteter weisser Strang zur hinteren Kante des oberen linken Lungenlappens, von da zum linken Herzohr, quer durch den linken Vorhof, durch das Septum beider Vorhöfe, durch den rechten Vorhof, und dann durch den entsprechenden Theil des parietalen Pericards, hier sich stark verjüngend, um endlich, am hinteren Rande des rechten oberen Lungenlappens, in ein entfärbtes Blutgerinnsel eingebettet, zu enden. - Lungen gut Iufthaltig. In den oberen Lappen stecknadelkopfgrosse Heerde an der Peripherie und Thromben (Emboli) in grösseren Zweigen der Art. pulmonalis. - Sonst keine Abnormitäten bei der Section zu entdecken.

Der Cg-Faden erscheint als ein mattweisser Axen-Strang in eine durchscheinende hellgraue Hülle eingebettet. Mikroskopisch stellen sich die Verhältnisse entsprechend dar: In der Mitte das an der Peripherie vielfach ausgebuchtete $\mathrm{Cg}$ umgeben von einer dicken Schicht von dicht an einander liegenden runden Zellen. Hierauf folgt nach aussen eine concentrische faserige Lage und ganz nach aussen eine Schicht zum Theil in Fibrin sich umwandelnder farbloser Blutzellen. Die concentrische Faserschicht ist von wenigen rundlichen Zellen durchsetzt; nur die 
imnerste Schicht derselben, nach dem Axenstrang zu, zeigt eine Infiltration mit runden Zellen, im Ánschluss an die das $\mathrm{Cg}$ direct einhüllende Zellenmasse.

Auch in Versuch 26 war ein Cg-Faden quer durch den Thorax gezogen worden. Section nach 61 Tagen. Das $\mathrm{Cg}$ geht als wachsbrauner, durchscheinender Strang quer durch beide obere Lungenlappen und zwar von der linken Lunge, zwischen V. pulm. und Aorta, dann zwischen Trachea und V. pulm. dxtr. hindurch, um sich im rechten oberen Lungenlappen einzusenken. Das Ende reicht hier frei in die rechte Pleurahöhle hinein. Weder am Lungengewebe noch an der Pleura, noch an den grossen Gefässen Veränderungen wahrnehmbar. - Nur wo das $\mathrm{Cg}$ über die Trachea weggeglitten war, erscheint es $\mathrm{zu}$ einem ganz feinen Strang verdünnt.

In zwei Fällen wurden dicke Cg-Stücke durch die V. jug. in die Lungencirculation eingeschoben (Vers. 23 und 25). Im ersten Falle fanden sich nach 25 Tagen zwei Cg-Stücke in Aesten der Art. pulm. im linken unteren Lungenlappen, ohne jede Veränderung des Lungengewebes. - Im zweiten Falle, nach 47 Tagen liess sich das $\mathrm{Cg}$ in dem sonst normalen Lungengewebe nirgends auffinden.

VIII. Aehnlich wie in die Brusthöhle wurde das $\mathrm{Cg}$ auch in die Bauchhöhle und die darin befindlichen Organe geführt. - An Fröschen wurden Präparate vom 4., vom 5., vom 12. und vom 21. Tage gewonnen (Vers. 16a, 15, 16b, 10 und 9). - In Versuch 16a war das Cg durch das Lumen des oberen. Jejunum gedrungen und durch das rechte Ovarium. An der Perforationsstelle des Darmes sulzige röthliche Auflagerungen und Verklebungen mit Leber und Milz. Der Darm oberhalb dilatirt, mit röthlichem Schleim gefüllt, seine Schleimhaut geröthet; unterhalb der Darm verengt. Tod am 4. Tage an diffuser Peritonitis.

Bei einem anderen Frosche (Vers. 15) ragte das $\mathrm{Cg}$ aus der Bauchhöhle in das rechte Blasenhorn. Tod nach 5 Tagen. - In Versuch 10 überlebte der Frosch die Operation 12 Tage. Das Cg drang hier vom linken Ovarium durch das Mesojejunum, unterhalb der $V$. portarum bis zum rechten Ovarium. I)as Cg erscheint makroskopisch unverändert, nur an der Stelle im Me- 
senterium spindelförmig verdickt. - Ëno ähnliche Verdickung zeigt das $\mathrm{Cg}$ in Vers. $16 \mathrm{~b}$, an den beiden Stellen, wo es durch das Duodenalrohr hindurchgeht, um weiter durch den rechten Leberlappen in die rechte Lunge zu dringen. Auch war das $\mathrm{Cg}$ hier bräunlich verfärbt innerhalb des Darmlumens und mit Kalksalzen incrustirt. - Das Thier überlebte den Eingrifi 11 bis 12 Tage. - Endlich der Frosch in Versuch 9 zeigt nach 21 Tagen den Cg-Faden eingekapselt an der Oberfäche des rechten Blasenhomes. - Die Präparate von Kaninchen stammen vom 31., 32., 33., 36., 64. und vom 82. Tage (Vers. 21, 20, 17, 18 und 12). - In Versuch 21 fand sich der Cg-Faden nach 31 Tagen im rechten Leberlappen an dessen convexer Oberfläche in sagittaler Richtung verlaufend. - Mikroskopisch erscheint auf dem Quer- und auf dem Längsschnitt das Cg ganz unverändert und in einer Hïlle von feinfaserigem Bingegewebe eingebettet, in welchem eine grosse Zahl theils zerstrenter, theils in Heerden angeordneter farbloser Blutzellen infiltrirt sind. Noch schönere mikroskopische Bilder, wo die Infiltrationszone in radiärer Richtung gegen das central gelegene $\mathrm{Cg}$ immer zellenreicher wird, ergeben die Querschnitte des $\mathrm{Cg}$ vorn 31. Tag aus Versuch 17. - 33 Tage nach Einführung eines ersten CgFadens quer durch beide Hypochondrien, wurde obiger Faden bei demselben Thiere (Vers. 17) quer durch die Mitte des Thorax in der Höhe der Zwerchfellskuppe durchgeführt. Dieser zweite Faden findet sich nach 31 Tagen an der Leberconvexität in Halbcirkelform eingebettet, z. Th. in die Lebersubstanz selbst eingesenkt. Das Zwerchfell intact. Der Cg-Strang erscheint hyalin, mit einer mattweissen Axe. Auf dem Querschnitt sehen wir unter dem Mikroskop das $\mathrm{Cg}$ eingebettet in eine verdickte Schicht, der Leberkapsel. Die bindegewebigen Schichten werden durchsetzt von Wanderzellen, die um das Cg selbst am reichlichsten angeordnet erscheinen und sich in die Buchten des $\mathrm{Cg}$ hineinlegen. Auch finden sich gerade am Rande des $\mathrm{Cg}$ mehrfach grosse mehrkernige Riesenzellen. Die Infiltrationszone trennt den $\mathrm{Cg}$-Faden von dem intacten Lebergewebe. - Der zuerst, also vor $33+31=64$ Tagen hindurchgezogene Cg-Faden Iag im Netz eingebettet an der hinteren Seite des Magens. Derselbe erscheint als cylindrischer Bindegewebsstrang, nur wenig 
durchscheinend, in dessen Axe nur stellenweise Reste des ursprünglichen $\mathrm{Cg}$ erhalten sind.

Das in Versuch 20 quer durch die Bauchhöhle geführte CgStück fand sich nach 32 Tagen ebenfalls im Omentum. Mikroskopisch finden wir um das $\mathrm{Cg}$ auch hier dieselbe Infiltrationszone mit reichlichen mehrkernigen grossen Zellen, dicht um das Cg herum, wie in Vers. 17 und 21.

In Versuch 18 war der Faden auch in frontaler Richtung vom rechten Hypochondrium nach links durchgeführt worden. Es fanden sich nach 36 Tagen knötchenartige Verdickungen der Serosa am Colon transv. Durch die Subserosa drang von hier aus in schiefer Richtung das $\mathrm{Cg}$ in's Darmlumen, wo dessen freies Ende in Koth eingehüllt war. Nach rechts hin lag der Cg-Faden vom hinteren Rand des rechten Leberlappens nach der Lumbalwand hin gerichtet und mit dem anderen Ende um die rechte Niere herum gebogen. Schnitte von dieser Stelle der Niere zeigen dieselben Verhältnisse wie diejenigen an der Leber. Das Nierengewebe ohne Veränderungen; in der unmittelbaren Nachbarschaft der Infiltrationszone ebenfalls ein grösserer Zellenreichthum im interstitiellen Bindegewebe. In Versuch 12 war einem jungen Kaninchen am 2. Juni 1874 ein $\mathrm{Cg}$-Faden frontal durch die Bauchhöhle gezogen worden. 49 Tage später wurde ein zweiter Faden in derselben Richtung durch den unteren Theil des Thorax hindurchgeführt. Der letztere blieb 33 Tage liegen und fand sich bei der Section zwischen Diaphragma und Leberoberfläche eingebettet, selbst nur peripherisch arrodirt, und wie oben, von einer Infiltrationszone umgeben. Der Cg-Faden rom 2. Juni (also nach 82 Tagen) wurde nicht aufgefunden.

Un das Verhalten des $\mathrm{Cg}$ in versehiedenen Flüssigkeiten zu prüfen, habe ich Ende Mai 1876 etwa $12 \mathrm{~cm}$ lange Stücke der dicksten Cg-Fäden, die auch sonst zu den Durchstichversuchen benutzt worden waren, in extsprechend hohen Stöpselgläschen aufgehängt. Ein Fadenende wurde am Stöpsel selbst an einer Oese befestigt; das andere Ende hing bis an den Boden des Gefässes herab und war durch Belastung mit einer Glaskugel daselbst festgehalten. - Das Gewicht der Kugel spannte den Faden, ohne ihn zu dehnen. - Als Medien benutzte ich 
destillirtes Wasser, 0,7 promillige Salzsäure, $\frac{1}{2}$ procentige Kochsalzlösung, menschlichen Harn, frisches nicht defibrinirtes $\mathrm{Ka}$ ninchenblut, frisches defibrinirtes Kaninchenblut, und solches defibrinirtes Kaninchenblut, das 24 Tage auf Eis gehalten worden war, frisches Kaninchenserum (24 Stunden auf Eis gehalten) und solches, das während 9 Tagen sich ausgeschieden hatte.

A. Nach 11 bis 13 Tagen zeigten sich die $\mathrm{Cg}$ Fäden gequollen: am meisten in $\mathrm{HCl}$, weniger im Harn, noch weniger in allen Blutsorten und in den Seren; am wenigsten in der $\frac{1}{2}$ procentigen Kochsalzlösung. - Nach etwa 18 bis 20 Tagen fand sich, dass unter Entwicklung von SH, das im frischen nicht defibrinirten Blut versenkte Cg roth imbibirt war. Dasselbe war im frischen defibrinirten Blute der Fall, nur die Imbibition schwächer, am stärksten am Boden der Flüssigkeit. An der Luftgrenze erschien das $\mathrm{Cg}$ mehr bräunlich. Auch hier fehlte der SH-Geruch nicht. - Der Cg-Faden im Harn zeigte sich zum Theil mit weissem Niederschlag, zum Theil mit Krystallplatten besetzt. Der Harn war klar und geruchlos und zeigte am Boden ein weisses Sediment von phosphorsaurer Ammoniakmagnesia.

B. Anfang Juli, nach 33 bis 36 Tagen erscheint das Cg:

1. In der 0,7 procentigen Salzsäure stark gequollen und aufgerollt. Die Reaction deutlich saner, ebenso leicht säuerlicher Geruch vorhanden.

2. Der Menschenharn zeigt alkalische Reaction, doch keinen Zersetzungsgeruch und ist klar. Das Cg stark gequollen, bräunlich verfärbt. Die Zahl der Krystallplatten an der Oberfläche des $\mathrm{Cg}$ vermehrt. - Der Spiegel der Flüssigkeit von einem feinen Häutchen bedeckt.

3. Das $\mathrm{Cg}$ im destillirten Wasser, dessen Reaction ganz schwach sauer, unverändert.

4. Im frischen nicht defibrinirten Blute ist die Reaction alkalisch; auch ist deutlicher Fäulnissgeruch wahrnehmbar. Die Flüssigkeit rubinroth, ein zartes lockeres Gerinnsel hüllt die Kugel ein. Das Cg leicht gequollen, schwach röthlich imbibirt, zeigt schwarze Marke an der Grenze zwischen Flüssigkeit und Luft. 
5. Im frischen defibrinirten Blute ebenfalls alkalische Reaction, SH-Geruch, dunkelrothe Farbe der Flüssigkeit. Das Cg wie oben.

6. Das frisch verwandte Kaninchenserum ist schwach alkalisch, geruchlos, gelblich gefärbt. Ein flockiger Niederschlag liegt am Boden.

7. Das Serum von dem älteren Blute verhält sich ähnlich; nur zeigt hier das $\mathrm{Cg}$ wieder eine schwarze ringförmige Marke an der Grenze von Luft und Flüssigkeit.

8. Das $\mathrm{Cg}$ im faulenden defibrinirten Blute hat, so weit es in Flüssigkeit eintaucht, seine Elasticität eingebüsst, riecht faulig und erscheint bräunlich gefärbt.

9. Das $\mathrm{Cg}$ in $\frac{1}{2}$ procentiger Kochsalzlösung erscheint wenig gequollen. Pilzwucherungen am Boden der sonst klaren, neutral reagirenden Flüssigkeit.

C. Am 21. Juli, nach circa 8 Wochen ist das $\mathrm{Cg}$ in der Salzsäurelösung stark gequollen, aber nicht schlüpfrig. - Im Harn hat sich ammoniakalischer Geruch eingestellt. Incrustationen und Krystallbildung reichlich am $\mathrm{Cg}$, seine Farbe bräunlich.

D. 16 Tage später, nach im Ganzen circa zehn Wochen, ist das $\mathrm{Cg}$ in der Salzsäure zwar immer noch gequollen, aber durchaus elastisch. - Im Harne sieht man ein reichliches krystallinisches Sediment von Trippelphosphaten. Daneben starker Ammoniakgeruch. - Das $\mathrm{Cg}$ in Aq. destillat. unverändert. Im ganzen Kaninchenblut hochgradige Fäulniss. Dem entsprechend auch das $\mathrm{Cg}$ matsch, in Fäulniss begriffen, und entzwei gerissen. Im entsprechenden Serum ein reichliches Sediment am Boden der röthlichen Flüssigkeit. Das $\mathrm{Cg}$ wenig gequollen. - Das Serum des älteren Blutes nicht röthlich, sondern harngelb, fast geruchlos, mit mässigem Sediment. Das $\mathrm{Cg}$ ist hierin nicht nur gequollen, sondern in beginnender $\mathrm{Ma}$ ceration. - Das 9 Tage alte Blut riecht jetzt stark nach alten Käse. Das $\mathrm{Cg}$ erscheint als zerreisslicher matscher dunkelrother Faden. Die Kochsalzlösung schwach nach Carbolsäure riechend. Dem $\mathrm{Cg}$ haften ähnliche Pilzwucherungen an, wie sie schon vorher am Boden der Flüssigkeit bemerkt worden waren.

E. Im A ugust 1881, also nach circa $5 \frac{1}{4}$ Jahren, ist der Befund folgender: 
1. Das $\mathrm{Cg}$ in 0,7 promilliger Salzsäure sehr stark gequollen, aufgedreht, nicht elastisch. Flässigkeit sauer, klar. Am Boden eine Wolke eines flockigen, leicht sich senkenden Niederschlages (Pilzwucherungen).

2. Das im Aq. destill. aufbewahrte $\mathrm{Cg}$ leicht gequollen, bräunlich, sehr fest, nicht elastisch. Die oberflächlichen Schichten macerirt; der Faden selbst nicht schlüprig.

3. Das $\mathrm{Cg}$ in frisch gelassenem Harne derb, elastisch, durchscheinend über der Flüssigkeit. In der Flüssigkeit rauh, grau gefärbt und incrustirt von dem krystallinischen Niederschlage, der am Boden der stark aromatischen, nicht ammoniakalisch riechenden, ganz klaren Harnflüssigkeit von braungelblicher Farbe und ausgesprochen saurer Reaction liegt. - Die obersten klaren Schichten der Flüssigkeit zeigen unter dem Mikroskop lange unbewegliche Stäbchen, kurze lebhaft und spontan sich bewegende biegsame Stäbchen und kleine Kugeln, theils in Haufen liegend, theils einzeln und mit Molecularbewegung. -Durch Bismarckbraun bei einfachem Zusata und nach Färbung getrockneter Präparate werden die Stäbchen und Körnchen nur ganz schwach gefärbt.

Der Niederschlag am Boden der Flüssigkeit weisslich, krystallinisch, zeigt unter dem Mikroskop Stäbchen und Körnchen in reichlichem Maasse, mehr wie an der Oberfläche der Flüssigkeit. Dann Körnchen in zooglöaartigen Haufen, innerhalb deren grosse braune Kugeln mit weissen Strahlen in Morgensternform besetzt, eingebettet sind. Die Grösse der Kugeln sehr variirend; daneben einzelne Krystalle in Wetzsteinform. Durcb Zusatz von Schwefelsäure werden weder die kugel- noch die wetzsteinförmigen Massen afficirt; nur die zooglöaartige Masse etwas aufgehellt. Dagegen entstehen schiefe Prismen von farblosen Krystallen und Nadeln, deren Länge an eimzelnen Stellen ïber das ganze Gesichtsfeld reicht. - Die Incrustirungsmassen des Fadens, zum Theil in Form von Platten am Faden sitzend, verhalten sich ebenso, nur herrschen hier die wetzsteinförmigen Krystalle völlig vor. Dieselben treten in schönsten Formen auf nach Aufhellung der Zwischenmasse durch Schwefelsäure. Durch Zusatz von $\mathrm{NO}_{5}$ werden der krystallinisehe Niedersehlag und die Pilzelemente ebenso wenig, verändert, wie durch die 
Schwefelsäure. Nur hören die Bewegungen der Stäbchen völlig auf.

4. Das $\mathrm{Cg}$ in $\frac{1}{2}$ procentiger Kochsalzlösung ist an der Flüssigkeitsgrenze zerrissen. Der oberhalb hängende Theil schwarz gefärbt, matsch, zerreisslich. Unter dem Mikroskop zeigen sich im zerzupften Präparate die Fasern von sporenähnlichen Zellenkugeln besetzt und von Pilzfäden, die aus Ketten bestehen, umwebt. Der Faden am Boden der Flüssigkeit in eine dicke Wolke grangefärbter Pilzmassen eingehüllt.

5. Das $\mathrm{Cg}$ im frischen Kaninchenserum erscheint oberhalb der Flüssigkeit bräunlich, weich und elastisch. In der Flüssigkeit weisslich, matsch, schlüpfrig aber fest. Das Serum braun, von säuerlich harnartigem Geruch, schwach sauer reagirend, nur schwach getrübt. Am Grunde ein weisslicher Bodensatz, ebenfalls aus Pilzmassen gebildet.

6. Das $\mathrm{Cg}$ im Serum, das 9 Tage vor der Einsetzung auf Eis aufbewahrt worden war, braun, so weit es in Flüssigkeit taucht gequollen und weich, aber sehr derb und nicht zerreisslich. Das Serum rothbraun, faulig riechend, alkalisch reagirend, undurchsichtig, mit weisslichem Bodensatz (Pilzwucherungen und verschiedene Krystallformen).

7. Das $\mathrm{Cg}$ in frischem defibrinirtem Blute erscheint fest, dehnbar und gequollen, schmutzig braun. Das Blut riecht faulig, deutlich nach $\mathrm{SH}_{2}$, in dicken Schichten schwarzroth, in dünnen schön carmoisinroth. Am Boden ein reichlicher brauner Satz. - Unter dem Mikroskop in der bräunlichen Farbstofllösung Pilzwucherungen und krystallinische Niederschläge, letztere auch am Faden haftend.

8. Das Cg im defibrinirten, nicht ganz frischen Blute abgerissen und matsch an der Flüssigkeitsgrenze, oberhalb fast ganz normal, hart und resistent. Die Flüssigkeit fast ganz eingetrocknet. In dem Flüssigkeitsrest Entwicklung von Schimmelpilzen. An dem zerzupften $\mathrm{Cg}$ keine Veränderungen wahrzunehmen.

9. Das $\mathrm{Cg}$ im frischen, nicht defibrinirten Blute matsch, an der Flüssigkeitsgrenze zerrissen, bräunlich, zeigt unter dem Mikroskop reichliche lange und dicke Stäbchen, feine Körner und Mycelienlager mit dergleichen Körnern zwischen den Fasern 
des aufgerollten Cg-Stückes. Das Blut selbst fürchterlich stinkend, ist schwarzbraun, lackartig, mit noch dunklerem, sehr reichlichem Bodensatz. - In Flüssigkeit and Bodensatz reichliche Entwicklung von Pilzen.

\section{Theil (Heteroplastik).}

Die Erfolge der Uebertragung völliger getrennter Hautstücke, welche letztere auf dem Anpflanzungsorte weiter Ieben und wachsen, legte den Gedanken nahe, auch andere Defecte, so besonders diejenigen der Knochen auf ähnlichem Wege auszufüllen. Das Einheilen von Kugeln in Knochen, das Verhalten von Elfenbeinzapfen in Bohrlöchern lieferten die ersten hier verwendbaren Erfahrungen. - Weitere Gesichtspunkte wurden aber eröffnet seit Einführung der antiseptischen Wundbehandlung. - Hatten die Versuche von Spiegelberg und Waldeyer u. A. nur die Art and Weise kennen gelehrt, wie Ligaturen einheilen können, so lernte man jetzt die Schicksale von Blutgerinnseln, todten Knochen- und Hautstücken u. s. f. kennen, wenn dieselben unter Ausschluss zersetzender Einflüsse mit lebenden Geweben in andauernder Berührung blieben. Hierzu kamen die Beobachtungen über die grosse Toleranz sehr empfindlicher Organe gegenüber absichtlich in dieselben gesenkten Fremdkörpern, falls nur der Wundverlauf ein aseptischer blieb. So können Drainröhren aus Gummi anstandslos selbst in Gehirnwunden gelegt werden (Socin). - Ja man hat interessante Fälle beschrieben, wo zufällig vergessene Gummiröhren, die als Drain's gedient hatten, völlig einheilten (Thiersch). - Endlich, nachdem bereits von Langenbeck und Nussbaum versucht hatten, Knochendefecte durch Hineinfügen von Knochenlappen aus den benachbarten Knochentheilen zu decken, zeigen die Versuche von Wolff, Bidder, Bruns, von Bergmann, sowie die operativen Versuche von Heine, Baum und Mac Ewen, dass auch die Transplantation von völlig getrennten Knochenstücken möglich ist.

Aelter als diese neuesten Resultate der Osteoplastik sind meine Versuche, um Defecte in den lebenden Geweben durch entsprechende Fremdkörper zu verschliessen. Diese Versuche, die ich mit dem Namen der Heteroplastik belegen möchte, 
stammen aus dem Sommer 1878. - Vier Fragen behielt ich zunächst im Auge

I. den Verschluss von Defecten im Schädeldach,

II. die Ausfüllung grösserer Substanzverluste in der Continuität von Diaphysen,

III. die Frage, ob es möglich sei durch Dnterfütterung, das Nachgeben von Narben zu verhindern, die einem dauernden Drucke ausgesetzt sind, wie wir solches besonders nach der Laparotomie an der vorderen Bauchwand und nach der Radicalbehandlung von Brüchen so oft in unerwünschter Weise beobachten.

IV. Ob Ersatz von verloren gegangenen Sehnenstïcken möglich sei.

Die Versuche wurden im Anschluss an oben erwähnte Erfahrungen zunächst mit durch längeres Aufbewahren in 5 procentiger Carbolsäure antiseptisch gemachtem Gummi und mit Kork angestellt. - In ein paar Fällen wurden auch Bleikugeln benutzt, aus nicht direct hierher gehörigen Gründen.

Der Gummi wurde in Form von Strängen zur Sehnenbildung, in Form von Pfropfen und kleinen Platten zum Verschluss von Trepanlöchern im Schädel, in Form von Cylindern zum Ausfüllen von Diaphysendefecten und in Form grösserer Platten zum Unterfuttern von Bauchnarben benutzt. - Den Kork wandte ich an, weil ich mir bei dessen wabenartigem Bau ein recht inniges Verwachsen desselben mit der Umgebung versprach durch Hineinwachsen von Granulationszapfen. Er wurde in Form von grösseren und kleineren Cylindern in Trepanlöcher am Schädel und auch an den Tibiae benutzt ${ }^{1}$ ).

1) Dem derzeitigen Standpunkte entsprechend wurde leider das Kochen der Korkstücke noch nicht geäbt. - Am Schädel wurden die Bohrlöcher mit dem Trepan angelegt, mit einer rundschneidenden Knochenzange erweitert. - Die meisten Versuche beziehen sich auf den Schädel, dann mehrere auf laparotomische Wunden, die wenigsten auf die Diaphysen, weil die Fixation der Extremitäten bei den Thieren nach Anlegung der Knochendefecte auf Schwierigkeiten stösst. - Doch wurde an den Extremitäten stets ein antiseptischer Verband angelegt. Am Kopf und am Bauche wurde von jedem Verbande abgesehen, dafür die Wunden durch tiefgreifende Matratzennähte aus Silber und feine Sibernähte der Haut verschlossen. - Die laparotomirten Thiere setzte ich auf antiseptische Polster von 10procentiger Salicyljute, 


\section{Zu den Versuchen wurden 6 Hunde und 8 Kaninchen benatzt.}

I. Verschluss von Trepanlöchern im Schädeldach durch Gummi, Kork (und Schrotkugeln).

Präparat vom 20. Tage (Hund V). - Am 22. Juni 1878 werden einem jungen lebhaften IIund rechts von der Crista sagittalis zwei Bohyöcher, links ein Bohrloch angelegt mit der Trephine. In das vordere Bohrloch rechts kownt ein ca. 2 mm hober Korkcylinder, in das hintere Bobrloch ein ebensolcher Cylinder aus Gummi. - Beide Cylinder hatten in sprocentiger Carbolsäure gelegen. In das Bohrloch links von der Sagittalnath wurde ein kirschkerngrosses Schrotikorn eingekeilt. Das Blei war mit 5 procentiger Carbolsäzre gekocht worden. - Die Matratzennaht löst sich bald. - Es tritt Retention von Secret ein, wodurch die Kopfhant in Form einer apfelgrossen Kuppe emporgehoben wird. Nach 4 Tagen entleert sich das riechende Secret durch den vorderen Wundwinkel. Nach 6 Tagen wird prima intentio nach Wegnahme der Nähte in der Hautwunde constatirt. Nur in der Mitte der Wundlinie entleert sich noch serös-blutiges Secret. -- Das Thier ist traurig, ohne Fresshust. Magert stark ab. - Es stellt sich eine phlegmonöse Schwellung bis zum Nasenrücken ein. - Am. 11. Juli wird die Wundhöhle ausgiebig gespalten. In derselben liegt die vordere Trepanöfnung durch eine Membran verschlossen zu Tage. Die Korkplatte fehlt. - Es besteht Husten und stöhnende Respiration. - Auspinselung der Höhle rait sprocentiger Chlorzinklösung. - Am 12. Juli, 20 Tage nach der Operation, Thier moribund. Section an demselben Tage nw 5 Chr Nachmittags. - Beide Plouren enthalten reichliche chocoladenfarbige Flüssigkeit; keine Auflagerungen auf den Pleurae costales, dagegen reichliche subpleurale, stecknadelkopfgrosse Heerde (Emboli) in beiden unteren Lungenlappen. Au der Vorderseite des mittleren Lappens ein grösserer, $1 \mathrm{~cm}$ tief reichender Heerd, gelblich mit bröcklichem Inhalt, der in die Pleura perforirt war. - Die beiden Trepanlöcher rechts durch bindegewebige Merbbranen verschlossen. Im hinteren liegt das unveränderte Gummistück frei beweglich. Die Knochenränder sind scharf, unverändert, die Membran schliesst sich dicht an die Lamina interna an, in der Fläche als deren Continuität erscheinend. - In vorderen rechten Bobrloch fehlt das Korkstück. Die obturivende Membran ist hier dicker, sie funlt fast die ganze Höhe des Bohrloches aus, indem die bindegewebige Masse vom Rande der Lamina ext. beginnend, nach der Mitte zu sich abflacht, an der Innenseite des Schädels aber wiederum in der Fuache der Lamina interna verlaufend. - Im linken Bohrloch steckt das Schrotkorn fest; es prominirt etwas gegen das Schädelinnere und ist an den Rändern, sowohl aussen am Schädel, wie innen, von einem Ringe einer bindegewebigen faserigen Masse eingefasst, die aussen vom Periost, innen von der Lamina int. ausgeht. - Die Dura zieht sich über alle drei Trepanlöcher hinweg. Nur unter dem rechten vorderen Loche (Korkcylinder) erscheint sie verdicht und blutig infiltrirt; auch liegt hier zwischen ihr und dem Fnochen ein Korkbröckel. Sonst ist die Dura intact. - Auch die Gehirnoberfläche 


\section{5}

erscheint makroskopisch unverändert. Doch findet sich zwischen ihr und der Dura reichliche trübe, schmutzigröthliche Flüssigkeit und ein frisches Gerinnsel im Sinus sagittalis. - Dagegen finden wir den Knochen um das mit Kork verstopft gewesene Bohrloch herum nach vorn, nach hinten gegen das hintere und nach links gegen das mit Schrot ausgefüllte Bohrloch hin, von Blntextravasaten durchsetzt, mit erweiterten Markränmen und vom $\mathrm{Pe}$ riost entblösst. Auch ist die Knochenoberfläche blutleer, trocken und an der Peripherie einer etwa 50 Pf.-grossen Fläche oberflächlich ausgenagt, als wenn an diesem Knochenstäck eine circumscripte Nekrose der Lamina ext. entstehen solite. - Offenbar ist in diesem Falle der Zutritt der pyämischen Complication durch das Kolkstück veranlasst worden, das zwar in 5 procentiger Carbolsäure gelegen hatte, nicht aber in derselben gekocht worden war.

Präparatvom 20. Tage. Weisses (albinotisches), kleines und schwächliches Kaninchen. - Am 2. Juli 1878 wird ein Hautschnitt // der Sutura sagittalis auf der linken Seite geführt, darauf die Kopfhaut nach rechts abgehoben und hier werden, rechts von der Sut. sagittalis, ara binteren Rande der Kranznaht zwei Bohrlöcher hinter einander gesetzt und durch Abzwicken der Knocbenzacken zu einer länglichen Oeffnung vereinigt, durch welche eine etwas grössere ovale, etwa $14 \mathrm{~mm}$ lange und $10 \mathrm{~mm}$ breite Gummischeibe eingefügt wird zwischen Dura und Knochen, so dass die Gummiplatte den ganzen Knochendefect deckt. Operationsdauer $\frac{1}{2}$ Stunde. Thier erholt sich gut. Nach 10 Tagen vollen Wohlbefindens prima intentio nach Entfernung aller Nähte constatirt. - Nach späteren 10 Tagen wegen profuser Diarrhöen dureh Genickstich getödtet. - Bei der sofortigen Section des an Enterokatarrh erkrankten Thieres zeigt sich die Gummiplatte fest eingekapselt, so dass die oberfächliche Kapselwand von einer derben bindegewebigen Membran gebildet wird, die aus Pericranium, Periost und der Knochensubstanz geliefert worden ist, während nach dem Schädelinnern die Gummiplatte direct der Lamina int. aufliegt und mit letzterer von der zarten bläulich durchscheinezden Dura überzogen wird. An dieser Stelle ist das Gehirn mit der Dura verklebt, sonst makroskopisch normal.

Präparat vom 21. Tage. Kaninchen 2, weiss, kräftig. Nachdem am 3. Närz 1878 am linken Bein nach Excision der Achillessehne ein Gummistrang an deren Stelle eingesetzt worden (s. u.), gescbieht dasselbe rechts am 3. April. Gleichzeitig werden in der Mitte der Ossa parietalia zu beiden Seiten der Sagittalnaht 2 Gummicylinder in Bohrlöcher gesetzt. - Der Wundverlauf kein aseptischer. - Nach 6 Tagen Thier abgemagert. Die Nähte aus der Kopfhaut entfernt und Auskratzen des käsigen Wundinhaltes. Auspinseln mit Perubalsam. - Das Thier leidet an profusen Diarrhöen. Auch der Wundverlauf an den beiden Beinen kein reactionsloser. Das Thier stirbt am 20. Tage naeh der Einsetzung der Gummicylinder. - Dieseiben sitzen scheinbar fest im Knochen eingekapselt. Aussen wird die Kapselwand von Weichtheilen und Periost gebildet; innen im Scbädel prominiren die Oylinder, besonder's rechts und wird hier die Kapselwand von 
einer doppelten Nembran gebildet, deren innerer dickerer Theil von der Lamina int. ausgeht und fibrös erscheint. Darüber zieht sich als aussere Hülle die durchscheinende Dura mater. Zwischen den Cylindern und der inneren Kapselwand ist käsiger Eiter angesammelt, der eine kuppelförmige Ausbuchtung der Kapselwand nach dem Gehirn zu bedingt. Die Lamina ext. und die Diploë erscheinen scharf begrenzt ohne jede Veränderung durch Gewebsneubildung. In der rechten Hemisphäre findet sich ein abgekapselter Heerd mit Käse, dicht unter dem nach der Schädelhöhle prominirenden Inhalt des Bohrloches im rechten Scheitelbein.

Präparat vom 30. Tage. Mittelgrosses, weisses, hochträchtiges Kaninchen 7. - Am 29. Juni 1878 Hautschnitt über dem rechten Os parietale, // der Sagittalnath. Zwei Bobrlöcher in's linke Os parietale, die zusammen zu einem länglichen Oval abgerundet werden. Hierbei findet im hinteren Wundwinkel ein Einriss der Dura statt. Einsehieben zwischen Dura and Schädel einer Gummiplatte, welche den Defect ausfüllt. - 2 Matratzen- und zahlreiche oberfächliche Nähte. - Nach 30 Tagen gestorben. - Die Gummiplatte liegt fest ein zwischen Dura und Knochen. - Knochenränder der Trepanöffnung scharf. Aussen am Schädel wird Oeffnung und Gummiplatte von den Weichtheilen gedeckt. Im Scbädelraum liegt zwischen Dura und Gummiplatte ein etwas geschrumpftes scheibenförmiges Blutgerinnsel, das sich auch falzartig zwischen Plattenränder und Knochenränder einschiebt. Atn Gehirn makroskopisch nichts Abnormes.

Präparat vom 33. Tage. Kräftiges, schwarzhaariges, mittelgrosses Kaninchen 5. - Am 30. Mai 1878 wird demselben eine Gummiplatte unter die laparotomische Wunde in der Linea alba unterfuttert. Das Thier bleibt munter. Am 18. Juni wird in ein Bohrlocb rechts von Sutura sagittalis ein Gummicylinder sehr prompt, aber etwas tief eingesetzt. Links ein zweites Bohrloch wird mit einem kegelförmigen Korkstück verstopft, mit der breiten Basis nach dem Gehirn zu, wobei letzteres etwas gequetscht wird, da beim Trepaniren die Dura einen Einriss bekommea hatte. - Bis zum 12. Juli 1878 das Thier sehr munter. Allein tief in den Bauchdecken hat sich ein knolliger Tumor gebildet. - Am 20. Juli, nachdem seit 3 Tagen der Bauchdeckenabscess aufgebrochen war, wird das Thier durch Genickstich getödtet. Sofortige Section. Befund der Bauchhölle siehe unten. - Gehirn makroskopisch normal. Der Korkkegel hat in dewselben eine tiefe Depression hervorgebracht. Es liegt hier dem Gehirn ein käsiges Flöckchen auf. Gummi und Kork fest im Schädel sitzend in bindegewebigen Kapseln, die von den durch Knochenwucherung verdickten Rändern der Trepanöffnungen ausgehen. $Z$ wischen Kork und Kapsel ein dünner Belag von geronnener Lymphe (zahlreiche weisse Zellen in einer körnigen Masse eingebettet, die durch A aufgehellt wird). Die Kapsel um den Gummicylinder erseheint doppelt so dick, als um den Korkkegel. - Das Periost aussen und die Dura innen überziehen als feine Lamellen die äussere und die innere Kapselwand, dieselben verstärkend. Ein paar Korkbröckel liegen in der Kapselwand dicht am Knochen fest eingehüllt (Fig. 2 a und Fig. 2 b auf Taf. X). 
Präparat vom 33. Tag. Altes Weibchen. Hund 2. Am 23. März werden Gummicylinder in beide Tibiae eingelegt in entsprechende Bohrlöcher. Carbolgazeverbände, nach 5 Tagen entfernt. Prima intentio. Am 5. April Einlegen von Gummicylindern zu beiden Seiten der Sagittalnaht in entsprechende Trepanlöcher. - Nach 5 Tagen Entfernung aller Nähte am Kopfe. Aus den geschwollenen Kopfdecken entleert sich viel viscide Flüssigkeit. Thier munter. - Nach 8 Tagen Thier sehr munter. Die Kopfwunde klafft, entleert gelbliche klare Flüssigkeit bei vollem Wohlbefinden. Am 8. Mai Thier verblutet. Rechts fehlt der Gummicylinder, links liegt derselbe in einer Kapsel eingeschlossen. Auf beiden Seiten geht die Dura glatt über beide mit fibrösen Membranen verschlossene Trepanlöcher hinweg. Die Membranen sind von der Lamina int. resp. der ihr anliegenden osteogenen Duraschicht und von einer Schicht Periost geliefert, so, dass die Membran in der Fläche der Lamina int. liegend, den Boden einer flachen Grube bildet, die an der Aussenseite des Schädels liegt und in der von einer Schicht Periost und Weichtheilen als äusserer Kapselwand bedeckt, links der Gummicylinder sich eingeschlossen zeigt (Fig. 3 auf Taf.X). Vom Knochenrand aus, als Product der Periostwucherung strahlt eine marginale Knochenwacherung in die obturirenden Membranen in Zackenform hinein. Besonders rechts sind diese Zacken von grösserer Dicke und Resistenz.

Präparat vom 40. Tage. Lebbafter junger Pinscher. Am 19. März wird in ein Bohrloch der Tibia eine Kugel von Blei eingeseblagen. Nach 8 Tagen ist dieselbe prima int. eingeheilt. Es beginnt aber anch die Kugel im Bohrkanal locker zu werden. - Am 23. März Kugel in linker Tibia. Keine prima intentio. - Am 5. April je ein Gummicylinder in die beiden Ossa parietalia in der Gegend der Tubera. - Am 9. April alle Kopfnähte entfernt. Viscide bräunliche durchscheinende Flüssigkeit aus der Kopfwunde ausgepresst. Sehr munter. Am 3. April prima intentio am Schädeldach. Am 8. Mai füblt man einen Gummicylinder mit der Kante unter der Haut aus dem Bohrloch prominirend. - Am 15. Mai (nach Transfusion von Blut) verblutet. - Die Section zeigt die Bohrlöcher durch Membranen verschlossen, die über die innere Schädeloberfläche hinweggehen. Aussen, am Schädel, etwas über die Bohrlöcher verschoben, liegen die Gummicylinder in bindegewebigen Hüllen eingekapselt. Hierbei zeigt sich, dass die Membranen als bindegewebiger Abschluss der Callusmassen dienen, welche die Knochenränder des Bobrloches in Form einer stumpfen Schneide abgrenzen. Nach dem Schädelinnern geht die Dura glatt über die Membranen bin. Aussen sind die Membranen innig mit dem Periost verschmolzen, wejches auseinanderweicht, um zwischen sich den Gummicylinder einzuschliessen (Fig. 4).

Das Verhalten der Bleikugel in einer Trepanöffnung ist an dem Präparate vom 20. Tage (Hund 5) bereits beschrieben worden.

Auch in Bezug auf Korkcylinder haben die Präparate vom 20. Tage (Hand 5) und rom 33. Tage (Kan. 5) das Nähere 
ergeben. - Wir haben nur noch das Praparat vom 16. Tage zu beschreiben.

Es betrifft ein ganz junges Hundeweibchen (Hund 3). Am 16. Mai 1878 Abends werden zwei Korkstücke, die in Thymol und 5procentiger Carbolsäurelösung eingelegt gewesen, in zwei Bobrlöcher, jedesmal nach Abhebung des Ansatzes rom M. terpp, eingesetzt. ZWwei Matratzennz̈hte und mehrfach $\theta$ Hautnähte aus Silber. - Ar 17. Mai heisse Nase, aber munter. Am 18. Mai Entfernung der beiden silbernen Matratzennähte, axp Tage darauf Entfernung der Hälfte der Hautnähte, nach weiteren 24 Stunden der übrigen Hautnăhte. Volle prima intentio trotz Scbwellung der Wundränder, die aber unempfindlich. - Am 30. Mai, bis wohin die Hündin ganz munter geblieben, wird ein Korlseylinder in die Mitte der trepanirten rechten Tibia gesetzt. Beim Trepaniren war aber das Schienbein ganz fracturirt worden. Es musste daher ein fixirender Schienenbindenverband angelegt werden. - Um den Verband zu ernenern, wurde am 1. Juni das Thier chloroformirt, wobei es in der Narkose zu Grunde ging. Unter dem Verbande zeigte sich das Oeden der Pfote im Zurückgehen und die Operationswunde am Bein reactionsios. Die beiden Korkcylinder liegen innerbalb der Bohrlöcher in bindegewebigen Kapseln, deren äussere Wand von der Musculatur, deren nach dem Schädelinnern gelegene Wand von dem Periost und von einer bindegewebigen Platte gebildet wird, die, wie es scheint, von der Dura geliefert, fest mit der Lamina int. verbunden ist. - Andererseits scheint das Periost zwischen Kork und Wand des Bobrloches sich eingeschoben zu haben, wăhrend die Knochenränder selbst ganz scharf begrenzt sich zeigen. - Die Dura liess sich leicht von der Innenseite der Bohrlöcher abreissen.

Möglicherweise wäre für die Korkpfröpfe auch eine niedrige Cylinderform mit Fussplatte zweckmässiger. Auch müsste der niedrige und scheibenförmige Pfropf golocht sein. - Vielleicht liessen sich die Korkpföpfe auch durch Knorpelplatten aus den Epiphysen wachsender Thiere ersetzen (Fig. 5).

II. Ersatz und Unterfütterung von Theilen der vorderen Bauchwand durch Gummiplatten nach Laparotomie.

Präparat vom 2. Tage. Erbsengelbes, sehr junges Kaxinchen 4. Nach Schnitt in der Linea alba wurde an der Innenseite der vorderen Bauchwand eine Gummiplatte hinter den Bauchmuskel-Peritonealründern durch Cg-Nähte befestigt (19. Mai 1878), d. h. dass die Hinterseite der Platte gegen die Därme sah, die Vorderseite an den Rändern der Serosa parietalis anlag, in der Vitte dagegen frei zwischen den ungeuähten Bauchmuskelrändern frei zu Tage lag. Die Haut wird dagegen durch Matratzenaähte und oberflächliche Knüpfnähte vereinigt. - Acuter Carbolismus, von dem sich das Thier in einer Stunde erholt. - Dann aber geht das Thier, theilweise unter Symptomen grosser Unruhe rasch zu Grunde. Es wird am 21. Mai todt gefunden. Es stellt sich heraus, dass eine Darmschlinge durch eine Cg-Naht 
fest an die Gummiplatte gedrückt worden war mit Unterbrechung des DarmJumens. - Die Wunde zeigt blutige Infiltration im oberen und im unteren Winkel. Coecum und Dünndarm sind mehrfach mit der Gummiplatte verklebt. - Aus der eingenähten Schlinge hatte sich fäcaler Inhalt in die Bauchhöhle entleert dureh eine Stichöffnung. Dabei pralle Füllung von Magen und Darm bis zur gekniekten Schlinge, Verklebungen einzelner Schlingen und alle übrigen Symptome einer jauchigen Peritonitis.

Präparat vom 19. Tag. Magerer, aber lebhafter; scheckiger Kaninchenbock (Kaninchen 6). - Am 5. Juni 1878 wird nach innen von der linken Reihe der Brustwarzen und // der Körperaxe ein Hautschnitt geführt, die Haut abgehoben und ein Muskelschnitt in der Linea alba mit Eröffnung des Peritoneum hinzugefügt. - Eine in 5procentiger Carbolsüure eingelegt gewesene Gummiplatte wird nun in der Weise an die Peritoneal-Muskelränder angenäht, dass die Mitte der Catgutschlinge die Platte allein in einiger Entfernung vom Rande fasst und dann erst durch den Peritonealınuskelwundrand geführt wird. So liegt der freie Rand der Platte ringsherum in einer Breite von $1 \mathrm{~cm}$ hinter den Wundrändern der Bauchwand (Fig. 6). Die Bauchmuskelränder werden ebenfalls durch Catgutnähte vereinigt. Dann folgen eine fortlaufende Matratzennath aus dickem Silber, und feine oberflächliche Nähte aus Neusilber, beide an der Haut. - Operationsdaner eine Stunde. Eine halbe Stunde nach Beginn der Operation und eine halbe Stunde nachdanernd acuter Carbolismus mit Bewusstlosigkeit, fortwährenden kionischen Krämpfen, Insensibilität der Corneae und weiten Pupillen. -Nachmittags Thier munter. - Nach 2 Tagen werden die Matratzennähte entfernt. Thier munter und fresslustig. - Das Wohlbefinden ist auch noch am 14. Juni zu constatiren. Indessen findet sich ein mit käsigem Inhalt gefüllter und geplatzter Abscess unter dem Lig. Poupartii links, eine zweite Perforation am Bauch am unteren Wundwinkel. Die Haut im Bereich der Nahtlinie zu einem schwarzen harten Schorf vertrocknet. - Um die Gummiplatte herum fühlt man eine wallartige Gewebsverdickung. - Das Thier stirbt am 24. Juni Abends. - Die Section ergiebt: die Banchböhle leer und durchaus ohne entzündliche Erscheinungen. Nur ein paar Colonschlingen und ein Stück Netz sind fest verwachsen mit der vorderen Peritonealwand, da wo dieselbe durch eine Verdickung des subperitonealen Bindegewebes verstärkt über die Hinterfäche der Gummiplatte weggeht, dieselbe völlig von der Bauchhöhle abschliessend. - Die Hinterwand und die falzartigen Seitenwände der Gummiplattenkapsel ist also vom subperitonealen Bindegewebe geliefert, die Vorderwand dagegen an den Rändern von den auseinandergewichenen Muskelrändern der Recti, während die Mitte der Platte nach vorn im käsigen Eiter liegt, der ringsum, auch hinten zwischen Peritoneum und Platte sich eingebettet findet. Die Catgutnähte fixiren sicher die Platte in ihrer Lage. - Ueber dem Abscesse liegt die Haut als mortificirter harter Schorf in der Ausdehnung eines 3 Markstücks, der nach rechts hin in Lösung begriffen ist, naeh links einen subcutanen kitergang nach dem Lig. Poup. sin. zeigt. Hier ist die Haut auch perforirt (Fig. 7). - Rechter Ho- 
den nomal. Linker Hoden bedeutend vergrössert, gangränös. Lungen blutreich. - Das Kaninchen war mit einem anderen Bock zusammengesperrt gewesen und hatte mit diesem gekämpft. (Sollte von der Hodengangrän die Abscedirung um die Gummiplatte mit abhängig sein? -)

Präparat vom 51. Tag. (Kaninchen 5.) - Mittelgrosses, schwarzhaariges, kräftiges Thier. Am 30. Mai 1878 Hautschnitt nach aussen von den linken Brustwarzen // der Linea alba. - Abpräpariren der Haut bis auf letztere, theikeise mit Abreissung, wobei ein paar Hautvenen mit Catgut ligirt werden. Bauchmuskeln in Linea alba getrennt. - Einschieben der präparirten Gummiplatte. Befestigung mit Catgutnähten an den Bauchmuskeln mit Durchstich der Serosa. In diesem Versuche wird die Naht der Bauchmuskelränder weggelassen, der Fautschnitt dagegen durch 2 tiefe und mehrere oberflächliche Nähte vereinigt. Am 3. Juni das Thier ruhig, aber munter. Die Hautwunde klafft bis auf die Wundwinkel. Die Wundränder der Haut wegen Constriction durch die Matratzennähte ödematös. Bauchmuskeln und Abdomen bei tiefem Drucke unempfindlich, nicht hart. - Am 14. Juni sehr munter. Am Banche kleiner Hautschorf. Bauchmuskeln weich anzufühlen. Hinter denselben eine Schwellung. - Nach Einfügung je eines Korkstückes und je eines Gummistückes in den Scbädel am 18. Juni, worauf das Thier wenig reagirt, findet sich am 12. Juli ein knolliger Tumor hinter den Baucbdecken. Derselbe, ein käsiger Abscess gebildet um die Gummiplatte, perforirt nach weiteren 3 Tagen nach aussen und wird daher am 20. Juli das Thier durch Genickstich getödtet. - Bei der sofortigen Section erscheinen Herz und Lungen normal. - Die Bauchhöhle ohne Flüssigkeit. In dieselbe reicht ein apfelgrosser Tumor der vorderen Bauchwand, an dem eine Schlinge des Coecum und einzelne Dünndarmschlingen adhäriren. Beim Abreissen der Adhäsionen reisst die Tumorwand ein und entleert gelblichen, nicht riechenden Eiter in das Cavum peritonei. Aus der nach aussen gerichteten Wand des Tumors fübrt ein subcutaner Gang gewunden bis zur Fisteloffnung am Bauche. - Innerhalb der von Flocken besetzten, ans diekem Bindegewebe bestehenden Kapselmembran des Tumors liegt frei die Gummiplatte, an der fast alle Nähte als Catgutschlingen sich befinden, nachdem wohl die Nähte überall durchgeschnitten hatten. Um die Gummiplatte reichlicher eiterähnlicher Inhalt. - Die Kapselmembran ist in toto vom subperitonealen Bindegewebe erzeugt (vgl. die zum vorhergehenden Versuch gehörige Fig. 7).

Präparat vom 60. Tage. Graues älteres Kaninchenweibchen (Kaninchen 3). - Am 4. Mai 1878 Eröffnung der Bauchböhle in der Medianlinie in $5 \mathrm{~cm}$ Länge. Prolaps der Därme, besonders des Coecum und des Colon. - Eine Gummiplatte eingeschoben und am oberen und am unteren Wundwinkel fixirt. Darïber werden die Muskelränder sammt Peritoneum zusammengenäbt mit Catgut. Hautnähte darüber aus Silber (8 an der Zahl). Nach 2 Tagen Thier sehr munter, fresslustig. Keine Schwellung der Wundränder. Am 8. Mai Entfernung der Silbernäbte. Hautwunde prima intentione verklebt, dagegen fühlen sich in der Tiefe die Muskelränder geschwollen an. 
- Am 19. Mai werden 2 Korkcylinder zu beiden Seiten der Crista sagittalis in das Schädeldach eingesetzt, noit nachfolgend reaetionslosem Wundverlauf. - Am 25. Mai werden fünf Fötus im Blechbecken gefunden (Thier war auf Salicyljute gebettet worden), zum Theil mit abgebissenen Extremitäten. Am 28. Mai 1878 ganz munter. Am Bauch ein dicker harter Schorf der Nahtlinie, in der Lösung begriffen. Hinter demselben tritt gelber rahmiger Eiter hervor. - Ama 14. Juni 1878 Thier sehr kräftig und munter. Am Bauche knollige Tumoren zu palpiren, mit' zum Theil von käsigem Eiter durchbrochenem Schorf bedeckt. - Tod am 3. Juli. Bei der Section zeigt sich die Gummiplatte fest an den Fäden innerhalb einer mit käsigem Eiter gefüllten Höhle haftend. Die vordere Wand des Abscesses wird von dem Hautschorf gebildet, die hintere zeigt eine wellige Form, ist durchschnittlich $1 \mathrm{~cm}$ dick, an einzelnen Stellen bis zur Grösse einer Haselnuss knollig verdickt und besteht nach der Bauchhöhle zu aus einer Schicht von fibrösem Bindegewebe, das ca. $4 \mathrm{~mm}$ dick ist, dem subperitonealen Bindegewebe entstammt und die Bauchhöhle völlig gegen den Abscess abschliesst. Einzelne Darmschlingen und das Netz sind mit dem parietalen Peritoneum an dieser Stelle fest verlöthet. Die innerste Schicht der Abscesswand ist 6-- $8 \mathrm{~mm}$ dick und erscheint makroskopisch von gelblicher Farbe.

Wahrscheinlich wäre auch hier die Anwendung dünner in 5procentiger Carbolsäure gekochter und gelochter Korkplatten zweckmässiger als diejenige von Gummiplatten gewesen.

III. Die Einfügung von Stücken von Gummi, Kork und Blei in die Tibia, sowie der Ersatz von Knochenstücken derselben durch Kork und Gummi.

A. Gummi. - Präparat vom 46. Tag. (Hund 2.) Am 23. März 1878 2 Gummicylinder in Trepanlöcher der vorderen Tibiawand eingefügt. Carbolgazeverbände. - Nach 5 Tagen Verbände entfernt. Prima intentio. - Am 5. April zwei Gummicylinder in's Schädeldach eingesetzt. - Am 10. April erscheint das Gummistück am rechten Bein fast völlig aus der Trepanöffnung unter die Haut herausgedrängt. Links weniger. - Am 13. April erscheint das Gummistück rechts ganz unter der Haut. - Am 8. Mai das Thier verblutet bei vollem Wohlbefinden. An der rechten Tibia der Gummicylinder in einer bindegewebigen Kapsel etwa 2,5 $\mathrm{cm}$ unterhalb des Bohrloches in Weichtheilen liegend. In das Bohrloch in der Corticalis senkt sich das Periost trichterförmig hinein und befindet sich in Zusammenhang mit einer fast die ganze Breite des Knochenmarks einnehmenden Zone von verknöcherndem, mit Kalk incrustirtem Gewebe. An der linken Tibia muss der Knochen beim Anlegen des Bohrloches fracturirt worden sein. Der Gummicylinder liegt hier in einer Bindegewebskapsel dicht unter dem Bohrloch, das sich hier als Fissur schief nach hinten und oben am Knochen fortsetzt. Die Fissur füllt eine verkalkende Bindegewebsmasse aus, die beiderseits mit dem Periost zusammenbängt, das ausserdem einen starken 
knöchernen Callus aussen und innen an der Knochenrinde un die Fissur geliefert hat (Fig. 9).

B. Blei. - Präparat vom 54. und 57. Tag. (Hund I.) Am 19. März 1878 nach Trepanation der rechten Tibia in der Mitte in Carbolsäure gelagerte Bleikugel von Kirschkerngrösse in das Trepanloch eingefügt. - Einbeilung prima int. Doch füngt nach 8 Tagen die Kugel sich subcutan an 2u. lockern.

Am 23. März Kugel in linke Tibia. Es tritt keine pr. int. ein und die Kugel fält heraus. - Am 5. April werden noch zwei Gummicylinder in's Schädeldach eingefügt. Am 13. April wird prima int. am Schädel constatirt. Thier ganz munter. - Am 8. Mai Kugel rechts locker unter der Haut. Links Wunde vernarbt, keine Kugel subcutan zu finden. - Thier sebr munter. - Nach Transfusion von $160 \mathrm{~g}$ Blut in V. jugul. aus der Carotis eines anderen Hundes (Vorlesungsversuch) wird der Hund an 15. Mai verblutet.

Das Präparak von der rechten Tibia vom 57. Tag zeigt die Kugel etwa $1 \mathrm{~cm}$ unterhalb der ursprünglichen Bohröfnung in eine bindegewebige Kapsel, die an einem stielartigen Fortsatz yon der Knochennarbe nach unten subcutan herabhängt. Die Knochennarbe selbst ist hohlkugelförmig vertieft, von narbigem Periost ausgefüllt; darunter liegt sclerosirter Callus als Continuität der Corticalwand, die in die Markhöhle selbst, fast deren halbes Lumen verlegend, hineinragt. - Links (Präparat vom 04 . Tag) fehlt die Kugel; die Verhältnisse am Knochen sind dieselben. Nur ist die Grube an der Stelle der Knochennarbe flacher. Auch finden sich in den corticalen. Callus Bleipartikel eingesprengt. - Die Bobrlöcher waren bis in die Markhöhle beiderseits gebohrt worden (Fig. 10).

C. Kork. - Präparate rom 3. Tage (Hund III). - Am 16. Mai 1878 Abends zwei Korkcylinder (in Thymol und 5 procentiger Carbolsäure aufbewahrt) beiderseits in 0 s tempor. eingesetzt. - Am 23. Nai Thier völlig munter. Die Korke prima int. eingeheilt (s. o.). - Am 30. Mai 1878 Korkcylinder von $6 \mathrm{~mm}$ Höhe in Trepanlöcher in der Tibia eingesetzt. Die Tibia beim Trepaniren fracturirt. - Aseptischer Verlauf, doch besteht Schmerzhaftigkeit wegen unvollkommener Immobilisation. Beim Versuch in der Narkose Bein besser zu schienen, geht das Thier asphyktisch zu Grunde. Das Präparat der Tibia bietet an der Operationswunde nichts Abnormes. Das Präparat vom 3. Tage, das yom Hunde 5 (alter, fuchsgrauer Hund mit Pneumonie) gewonnen wurde, hat nur Interesse wegen der Anordnung des Korkes. Das Thier ging am 3. Tage nach der Operation bereits zu Grunde. - Am 14. Juni wurde nehmlich von der Tibia ein ca. $1 \mathrm{~cm}$ hoher horizontaler Ring aus der ganzen Dicke des Knochens entfernt. Als Hülse für die Knochenstümpfe diente nun. eine Korkhülse mit in der Mitte eingepresstem dünnerem Korkcylinder (Fig. 12).

Das Präparat vom 39. Tage von der Tibia ist von Hund 4 gewonnen. - Dieser ganz junge Schäferhund erhäIt nach Trepanation der rechten 
Tibia in der Mitte einen Korkcylinder eingedrückt am 4. Juni 1878. Hierauf dreischieniger Fixationsverband, womit Thier gut herumläuft. Fresslust. - Hund zernagt den Verband, erhält daher am 14. Juni neuen Schienenverband. Thier munter. Wunde fast gar nicht secernirend, klafft in der Mitte, die Ränder pr. int. verheilt. Nach 3 Tagen, wo das Thier Verband wieder abgestreift, Wundsecret chocoladenfarbig; entleert sich auch ferner aus der fistelartig verkleinerten Wunde. - Da das Thier ganz munter, so wird am 21. Juni versucht Kork- und Gummiplatten in ein Bohrloch im Sternum einzufügen. Allein die Trepanation des Knorpels misslingt. Es können durch das Loch im Sternum nur ein paar Schrote peripherisch nach rechts eingeschoben werden. - Am 28. Juni ist die Sternalwunde abgeschwollen, es entleert sich nur ein Tropfen Eiter zwisehen den Wundrändern. Doch ist der weitere Verlauf ungünstig und zwar durch septische Veränderuingen in der Tibiawunde bedingt. - Ieh finde am 12. Juli 1878 das Thier traurig, matt, obne Fresslust, abgemagert. Dieser Zustand soll seit Anfang Juli bestehen. Aus der Brustwunde entleert sich sparsame gelblich dünueitrige Flüssigkeit. - Das rechte Bein wird angezogen gehalten. Die Wandumgebung ist nicht sehmerzhaft, nicht geschwollen. Secret missfarbig, aber sparsam. - Nach Dilatation der Wunde werden zwei nekrotische Knochenringe aus derselben herausgezogen. Auspinselung mit 8 procentiger Chlorzinklösung. - Tod an 12. Juli Nachmittags 4 Uhr an Sepsis und sofortige Section. - Der Kork findet sich in einer kirschgrossen, von bräunlicher Membran ausgekleideten Abscesshöhle freiliegend. In die Höhle ragen, wie in einen pseudarthrotischen Sack, die durch compacten Callus verschlossenen und abgerundeten Knochenstümpfe. Das Knochenmark reactionslos. Kniegelenk und Fussgelenk frei. Fine Stütze erhielt die Exxtremität dadurch, dass die Fibula ganz geblieben war. Doch zeigt sich dieselbe eingebogen (Fig. 11).

IV. Es erübrigt noch die Beschreibung zweier Versuche, wo ich nach Excision der Achillessehne beabsichtigte dieselbe durch Gummistränge zu ersetzen.

Bei Kaninchen I, einem grauschwarzen, kräftigen Thiere waren am 23. März 18782 Gummipfröpfe in die Ossa frontalia eingesetzt worden. Bei aseptischem Wundverlauf folgte am 30. März 1878 der Ersatz der linken Achillessehne durch einen Gummistreifen. Nach Schnitt auf die Sehne oberhalb des Calcaneus wurde ein Stück derselben resecirt und dann ein Gummistreifen subeutan neben den Wadexmaskeln, wie bei einer subcutanen Schnürnaht so durchgefübrt, dass die Ansa des Fadens quer durch den oberen Ansatz der Wadenmuskeln ging, die beiden freien Knden des Fadens zur Wunde über dem Calcaneus hervorsahen. Schliesslich wurden letztere um den Calcaneus herumgeschlungen und geknüpft. - (Operation am 30. März 1878.) Die Wunde über der Sehne wird vernäht. Am 11. April 1878 ist das Thier munter, das Bein abgeschrollen.

Am 13. April löst sich mortificirte Haut im Bereiche der Nahtlinie am 
Bein. Gleichzeitig schwillt das Bein etwas an und ein Fadenende (wahrscheinlich nach Lösung des Knotens um den Calcaneus) wird sichtbar. Am 17. April kamn ein Theil des Gummifadens (wahrscheinlich Alles!) herausgezogen werden. - Das Thier wird matt und stirbt am 20. April nach proIusen Durchfällen. - Ausser dem Schädelpräparat (vom 28. Tage) findet sich am Bein kein Gummistreifen mehr. - In Folge mangelbafter Fixirung des Gummistreifens am Calcaneus, waren dessen untere Enden zurückgeschlüpft und aus dem bindegewebigen Kanal, in dem der Faden an der Aussenseite der Wadenmuskeln gelegen, herausgezogen worden.

Die beiden anderen Präparate sind von Kaninchen 2 gewonnen worden. - Den weissen Kräftigen Kaninchenbock wurde am 23. März 1878 die linke Achillessehne in der Weise ersetzt, dass zunächst die Haut des Unterschenkels yon der Fossa poplitea bis herab zum Calcaneus in der Längsaxe des Gliedes gespalten wurde mit Abpräpariren derselben nach rechts und links. Hierauf Excision der Achillessehne und Einfügen des Gummistranges in der Weise, dass die Ansa desselben beabsichtigter Weise quer durch einen horizontalen Bohrkanal in der Femurepiphyse, die freien Enden durch ein Loch im Calcaneus geführt und geknüpft wurden.

Am 3. April 1878 folgte der Ersatz der rechten Achillessehne. Nach Spaltung der Haut bis über das Kniegelenk hinauf, an der Hinterseite der Extremität, wurde mit Drillbohrer ein Loch quer durch beide Condylen des Femur und ein Loch durch den dünnen brüchigen Calcaneushöcker gebohrt. - Den Gummistrang fübrte ich quer durch den Bohrkanal in der Femurepiphyse, knüpfte ihn zu einem Ring unter den Wadenmuskeln und führte die freien Enden herab bis zum Calcaneus, wo dieselben nacb Durchführıng durch den Bohrkanal wieder geknüpft wurden. - Rechts, wie früher links, wurde nun die mantelartig abpräparirte Haut über den Wadenmuskeln wieder vereinigt (Fig. 13). (Ausserdem wurden dom Thier 2 Gummipfröpfe zu. beiden Seiten der Crista sagittalis in die Ossa parietal. gesetzt.) - Vorn Kopfe aus entwickelt sich ein schleichend septischer Zustand. Am 10. April fängt der Hantschorf am linken Bein in der Nahtlinie an sich zu lösen. Er fällt am 3. April ab und der Gummistreif liegt am Tuberc. calcanei frei $z u$ Tage. - Das rechte Bein ganz abgeschwollen, nur der Caleaneus ist hier in der Planta schmerzhaft. - Am 24. April stirbt das Thier. - Das Schädelpräparat vom 21 . Tag zeigt die Gurrmipfröpfe fest in Kapsein im Knochen liegend, aber in Käse eingebettet. - Ein abgekapselter, Käse enthaltender Heerd unter der Oberfläche der rechten Hemisphäre, dicht unter dem etwas nach der Schädelhöhle eingedrückten rechtsseitigen Gummipfropf. - Die Gummistränge sind sowohl am linken Bein (28. Tag) wie am rechten Bein (21. Tag) prima intentione eingeheilt. Doch ist der Calcaneushöcker beiderseits nekrotiseh. Daher hat sich der Gummistrang an beiden Seiten etwas zurückgezogen innerhalb der am tibialen und am fibularen Rande der Wadenmuskeln gebildeten bindegewebigen Hohlkanäle (artificielle Sehnenscheiden). - Am linken Bein war der Bohrkanal oberhalb der Waden- 
muskeln blos durch Condyl. ext. tibiae gegangen. - Rechts durchdrang der Bohrkanal quer die Femurepiphyse ohne entzündliche Erscheinungen daselbst und im Kniegelenk. Dagegen findet sich an der Aussenseite des Kniegelenks ein käsiger Senkungsabscess, der bis zur Mitte des Oberschenkels reicht, ja bis zur Symphyse hinauf sich erstreckt.

A nhang. Beim Hunde IV endlich, nachdem am 4. Juni 1878 an Stelle eines heraustrepanirten Knochencylinders aus der Mitte der rechten Tibia versucht worden war, ein entsprechendes Stück Kork einzusetzen, wurde am 21. Juni 1878 nach Freilegung des Sternum in demselben eine Oeffnung angebracht (das Trepaniren des Knorpels gelang schlecht) und ich schob durch die Oeffnung 2 desinficirte Bleisehrote nach rechts subpleural ein.

Am 22. Juni ist das Thier munter, zeigt aber eine heisse Schnauze. Die Wunde etwas geschwollen. Am 28. Juni wird nach Entfernung der Nälbte ein Tropfen Eiter zwischen den Wundrändern entfernt. Am 10. Juli ist das Thier matt, ohne Fresslust und abgemagert. Es besteht Zersetzung in der Wunde an der Tibia. Am 12. Juli stirbt das Thier. An der Tibia finden sich die Knochenstümpfe durch compacten Callus verschlossen. Das Knochenmark nicht geröthet. Knie- und Fussgelenke frei. Die Knochenstïmpfe ragen in eine Abscesshöhle hinein, deren Wand von einer bräunlichen, nissfarbigen Membran gebildet wird. Letztere überzieht auch die Knochenstümpfe (s. o.). Eine ähnliche Abscesshöhle findet sich auch am Sternum. Die hineinragenden Rippenknorpel wie der angrenzende Knorpel des oberen Sternalstücks unverändert. Das untere, an das Loch angrenzende Sternalstück röthlich und zerfasert. In Pericard und Pleuren keine Veränderungen. Die beiden Bleischrote rechts vom Sternum subpleural eingekapselt. Lungen ohne Veränderungen. An Herzfleiseh, an Leber, Milz, Nieren und Darm Veränderungen, wie sie der Septicämie entsprechen.

Die im I. Theil beschriebenen Versuche über das Verhalten des $\mathrm{Cg}$ im Organismus verdienen die wenn auch verspätete Veröffentlichung aus mancherlei Gründen. Zunächst wegen der Methode des Einführens des $\mathrm{Cg}$ in den Thierkörper mittelst subcutanen Durchstichs, wodurch der aseptische Verlauf des operativen Eingriffes im Voraus gesichert wird. Sodann wurden nur ein und dieselbe Sorte $\mathrm{Cg}$, also von derselben Bereitungsweise und nur eine Art Thiere von annähernd gleichem Alter und gleicher Beschaffenheit verwendet. Die sich hierbei für das $\mathrm{Cg}$ ergebenden Differenzen können bei gleichem Alter der Versuche nur auf das verschiedene Verhalten der Organe resp. Gewebe gegen das $\mathrm{Cg}$ bezogen werden.

Es ist richtjg, dass heute das $\mathrm{Cg}$ immer mehr von der in 5-10procentiger Carbollösung gekochten Seide als Ligatur- und 
als Nähmaterial verdrängt wird. - Immerhin ist es von allgemeinem Interesse, mit Rücksicht auf den Verlauf von Resorptionsvorgängen im Organismus, zu sehen, wie je nach der angewendeten Versuchsmethode die Ergebnisse so ganz verschieden sich gestalten. - Haben auch meine Versuche das Endergebniss geliefert, dass das Cg nicht "organisirt", in "lebendes Gewebe" verwandelt, sondern "resorbirt" und durch "einen Narbenstrang substituirt" wird, so ist doch auffällig, im Gegensatz zu allen anderen Experimentatoren, wie lange der Cg-Faden der Zerbröckelungsarbeit der zelligen Gewebselemente widersteht. Befördert und beschleunigt wird dieser Vorgang an solchen Orten, wo das $\mathrm{Cg}$ einer Zerrung oder Reibung ausgesetzt ist, z. B. durch Gewebsquellung oder durch dauerndes Wegleiten des $\mathrm{Cg}$ über Knochenvorsprünge. - Am raschesten verliert das $\mathrm{Cg}$ seine Widerstandsfähigkeit bei nicht aseptischem Wundverlauf, was übrigens anch durch das Verhalten des $\mathrm{Cg}$ in faulendem Blute nur bestätigt wird. - Mit anderen Resorptionsvorgängen, an Blutextravasaten, Hautfetzen, Knochenstücken, Elfenbeinstiften u. s.f. haben diejenigen am $\mathrm{Cg}$ auch das gemein, dass grossen, Osteoblasten-, Osteoklasten- oder Myeloplaxen-ähnlichen Zellen dabei eine wesentliche Rolle zukommt. (Vgl. L. von Lesser, ïber lebensrettende Operationen, F. C. W. Vogel, Leipzig 1880, S. 200.)

Die im II. Theile wiedergegebenen Versuche über Heteroplastik haben auf die aufgestellten Fragen - wie zu erwarten gewesen - nur eine relativ bejahende Antwort gegeben. Immerhin sind die Versuchsergebnisse interessant genug für eine Veröffentlichung. - Muss man dieselben auch zum Theil als Vorversuche auffassen, insofern als erst eine vollkommenere Ausführung derselben die gewünschten Resultate liefern dürfte, so ist die Berichterstattung darüber schon um deswillen geboten, um Anderen, die etwa ähnliche $W$ ege einschlagen möchten, eine Zahl von bereits gemachten Erfahrangen zu ersparen. Ich möchte auch vorläufig von einem Zusammenfassen der Versuchsergebnisse absehen und nur Einzelnes hervorheben. - Das Einheilen von Platten unterhalb von Trepanöffnungen zwischen Schädeldach und resp. dem Gehirn, scheint möglich zu sein. - Die Versuche über die Verlegung von Trepanlöchern im Schädel und 


\section{7}

in der Tibia mittelst Gummipfröpfen, Korkcylindern und Bleikugeln bestätigen die Angaben von Maas, über die Rolle des Periostes bei der Knochenregeneration. - Interessant ist die Auspressung der verstopfenden Fremdkörper aus den Trepanlöchern. - Das nicht Einheilen der Gummiplatten in oder hinter der Bauchwand war offenbar durch die nicht streng aseptische Beschaffenheit der Platten bedingt. Die Platten verhielten sich in Betreff der Abscessbildung, wie wir es früher an den nicht gekochten Seidenligaturen für den Ovarialstiel gesehen haben, die so oft unter Bildung jener in Vagina oder Rectum perforirender perimetritischer Abscesse zur Ausstossung gelangten. - Rein aseptisches Material müsste, etwa wie die Bardenheuer'schen Gitter volle Einheilung ergeben.

Zur Ausfüllung von Defecten in der Continuität von Diaphysen dürfte die Einpflanzung lebenden Knochengewebes den Vorzug verdienen, wie es auch die Erfolge beim Mensehen zeigen. (Vgl. auch meinen Fall von Ersatz der Grundphalanx des rechten Zeigefingers durch einen Knochencylinder aus der Tibia. Bericht über fünf Jahre poliklinischer Thätigkeit in Leipzig. - Leipzig 1883, F. C. W. Vogel.) - Das Weglassen einschlägiger Literaturangaben geschah aus Raumersparniss.

\section{Erklärung der Abbildungen.}

Tafel X.

Fig. 1. Schema der subcutanen Einheilung eines Catgutfadens. a Catgut; b b dreikantige mit weissen Blutzellen erfüllte Räume. c c Blutextravasate, d d weisse ausgewanderte Blutzellen.

Fig. 2 a , 2 b, 3 und 4 beziehen sich auf Einheilung von Gummipfröpfen oder Korkcylindern in's Schädeldach. Zeichnungen ebenfalls schematisch gehalten. In diesen Figuren bedeutet a die Schicht der Weichtheile auf dem Schädeldach, b das epicranielle Periost, c die Schädelknochen (im frontalen Durchschnitt), d Dura mater, e Gummipfropfen, f Korkcylinder, k Korkbröckel, $m$ Verschlussmembran des Trepanloches, n Kapsel um den Gummipfropf, o o strahlig in die Membran $\mathrm{m}$ rom Knochen-Periostrande hineinwachsende neugebildete Knochensubstanz.

Fig. 5. Ein gelochter Doppeleylindẹ aus Kork zum Tẹtschluss von Trepanlöchern im Schädel. 
Fig. 6. Unterfutterung eines Schlitzes in der vorderen Bauchwand mit einer Gummiplatte.

Fig. 7. Einkapselung einer Gummiplatte hinter der Bauchwand (Schema im Erontalquerschnitt). e Gummiplatte, h Hautdecke, s Hautschorf, $m$ Bauchmuskelwand, $p$ Peritoneum, k Kapsel.

Fig. 8 a und 8 b. Art der Finnähung einer Gummiplatte hinter der Bauchwand. e Gummiplatte, m Bauchmuskeln, n Catgut- oder Seidenschlinge.

Fig. 9. Gummipfropf, herausgedrängt aus einem Trepanloch der Tibia. c Callus, p Periost, m innerer (Mark-) Callus, $k$ Ausfüllungsmasse im Trepanloch, e Gummipfropf.

Fig. 10. Kugel, herausgedrängt aus einem Trepanloch in der Tibia. p Periost, $\mathrm{k}$ Knochennarbe im Trepanloch.

Fig. 11. Pseudarthrose der Tibia, durch Einpflanzung eines Korkcylinders erzengt. f Korkcylinder.

Fig. 12. Schema einer Korkhülse für Ausfüllung eines cylindrischen Defects aus der Tibia.

Fig. 13. Schema für den Ersatz der Achillessehne durch einen Gummistrang. 